\title{
Corrosion Inhibition of Mild Steel in Acidic Media by $N$-[(3,4-Dimethoxyphenyl)Methyleneamino]-4-Hydroxy-Benzamide
}

\author{
Kashmitha Muthamma ${ }^{1} \cdot$ Preethi Kumari $^{1} \cdot$ M. Lavanya ${ }^{2} \cdot$ Suma A. Rao $^{1}$ \\ Received: 19 June 2020 / Revised: 7 October 2020 / Accepted: 14 October 2020 / Published online: 1 November 2020 \\ (c) The Author(s) 2020
}

\begin{abstract}
Mild steel (a low carbon steel) is an affordable engineering material used for many purposes in various environments including mild acidic environment with some precautions. The corrosion behaviour of mild steel (MS) in $0.5 \mathrm{M} \mathrm{H}_{2} \mathrm{SO}_{4}$ and $0.5 \mathrm{M}$ $\mathrm{HCl}$, in the temperature range (303-323 K) without and with the inhibitor $N$-[(3,4-dimethoxyphenyl) methyleneamino]4-hydroxy-benzamide (DMHB), was investigated using Potentiodynamic polarization and Electrochemical impedance spectroscopy (EIS) techniques supplementing with surface characterization study using scanning electron microscope (SEM) and atomic force spectroscopy (AFM). Experimental observations were found to be in agreement with Density functional theory (DFT) calculations. The inhibition efficiency increases with increase in DMHB concentration and showed maximum inhibition efficiency of $86 \%$ in $0.5 \mathrm{M} \mathrm{H}_{2} \mathrm{SO}_{4}$ and $81 \%$ in $0.5 \mathrm{M} \mathrm{HCl}$, respectively, at concentration of $3 \times 10^{-3} \mathrm{M}$ at $303 \mathrm{~K}$. The inhibition efficiency of DMHB obtained relatively at its lower concentration $\left(3 \times 10^{-3} \mathrm{M}\right)$ compared to other reported related compounds confirms its potential towards corrosion inhibition. The variation in the kinetic and thermodynamic parameters indicated physisorption of DMHB on MS and its mixed type inhibitive action followed Langmuir's isotherm model. DFT calculations go along with the experimental results, signifying the potential corrosion inhibition behaviour of DMHB for MS in both the acid media.
\end{abstract}

Keywords Mild steel $\cdot$ Impedance $\cdot$ Physisorption $\cdot$ Langmuir isotherm

$\begin{array}{ll}\text { Abbreviations } \\ \text { MS } & \text { Mild steel } \\ \text { DMHB } & N \text {-[(3,4-Dimethoxyphenyl }) \\ & \text { methyleneamino]-4-hydroxy-benzamide } \\ \text { SEM } & \text { Scanning electron microscope } \\ \text { AFM } & \text { Atomic force microscope } \\ \text { DFT } & \text { Density functional theory } \\ \text { EIS } & \text { Electrochemical impedance spectroscopy } \\ \mathrm{HCl} & \text { Hydrochloric acid medium } \\ \mathrm{H}_{2} \mathrm{SO} & \text { Sulphuric acid medium } \\ \mathrm{PDP} & \text { Potentiodynamic polarization } \\ \mathrm{OCP} & \text { Open-circuit potential }\end{array}$

Suma A. Rao

suma.rao@manipal.edu

1 Department of Chemistry, Manipal Institute of Technology, Manipal Academy of Higher Education, Manipal 576104, India

2 Department of Chemical Engineering, Manipal Institute of Technology, Manipal Academy of Higher Education, Manipal 576104, India

\author{
$E_{\text {corr }}$ Corrosion potential \\ $i_{\text {corr }} \quad$ Corrosion current density \\ CR Corrosion rate \\ $\%$ IE Percentage Inhibition efficiency \\ $\theta \quad$ Surface coverage \\ CPE Constant phase element
}

\section{Introduction}

Mild steel is an affordable engineering material by virtue of its properties such as strength, ductility, toughness, malleability, machinability and weldability. It finds applications in automobile body components, structural shapes, sheets, etc. The microstructure consists of ferrite and pearlite and has tensile strength in the range 415-550 MPa [1]. Material is used in various environments including mild acidic environments and can undergo electrochemical oxidation resulting in destruction of metal. This corrosion induced in the material, besides loss in weight and cross section, can lead to hostile effects on the material properties [2] Corrosion of MS is an important problem in industrial processes having acid environment. In the construction of oil, gas or 
water wells, pickling acid washing, matrix acidizing and acid fracturing are operations performed during the production stimulation processes [3]. Generally, acid solutions are used at room temperature for removing soil and light rust [4]. For example, in acid pickling, these are widely used as it is more economical and trouble free. The main advantage of these acids over other acids in cleaning and pickling operations lies in their ability to form metal chloride and metal sulphates which are fairly soluble in aqueous medium, compared to phosphate, nitrate and sulphamate ions [5]. But extreme care has to be taken in handling it even in small concentration as it is corrosive to many metals including MS. Hence, the destruction in acid environment is more crucial to be addressed as huge amount of material loss occurs worldwide due to acid wash every year.

Even though various techniques like surface modifications, anodic and cathodic protections, and coating (painting) for the metal are available, the use of inhibitors in the medium is found to be one of the simple and cost-effective choices to protect metals against corrosion, particularly for a closed system [6]. Some organic compounds containing electron donating groups or polar functional groups, heteroatoms, aromatic rings with $\pi$ - electrons are widely used as effective corrosion inhibitors in industrial applications for various metals including MS. These inhibitors get adsorbed on the metal surface either chemically or physically forming a blanket on the metal surface, and thus isolate metal from the corrosive ions present in the medium [7, 8].

The well-known biological applications of hydrazides and their condensation products are in using them as antibacterial, antituberculosis and antifungal $[9,10]$. The chemistry of - $\mathrm{CN}$ group of hydrazides is becoming the backbone of condensation reaction in benzo-fused heterocycle [11] and also it constitutes an important class of compounds for developing new drugs [12]. The ability of the hydrazide derivatives [13-17], thiosemicarbazide derivatives, thiosemicarbazone, hydrazone derivatives [18-21] to inhibit corrosion of MS in acid medium is well established due to the presence of electron donating groups, heteroatoms, $\pi$ - electrons and lone pair of electrons in them. The formation of an adsorption film on the metal surface is determined by the planarity of the entire structure of the compound [22,23].

Saliyan et al. $[13,20]$ have investigated the effect of quinoline-based hydrazide derivatives $(\mathrm{QH} 1$ and $\mathrm{QH} 2)$ on mild steel in $\mathrm{HCl}$ and $\mathrm{H}_{2} \mathrm{SO}_{4}$. QH 1 showed the maximum efficiency of $90.8 \%$ in $1 \mathrm{M} \mathrm{HCl}$ and $86 \%$ in $2 \mathrm{M} \mathrm{HCl}$ at $500 \mathrm{ppm}$, respectively, whereas $\mathrm{QH} 2$ showed maximum efficiency of $94.8 \%$ in $1 \mathrm{M} \mathrm{HCl}$ and $98.5 \%$ in $0.5 \mathrm{M} \mathrm{H}_{2} \mathrm{SO}_{4}$ at $11.086 \times 10^{-4} \mathrm{M}$ at $60{ }^{\circ} \mathrm{C}$, respectively. The influence of $N^{\prime}$-(4-methoxybenzylidene) benzohydrazide as corrosion inhibitor for mild steel in $1 \mathrm{M} \mathrm{HCl}$ was studied by Mohan et al. [14]. The inhibitor showed maximum IE of $93 \%$ and followed Langmuir's adsorption. Several benzohydrazide derivatives were studied as potential inhibitors towards steel corrosion in $\mathrm{HCl}$ medium by Fouda et al. [15]. All the studied compounds exhibited an average IE in the range of $80 \%$ at their optimum concentration. The adsorption takes place through physisorption and obeyed Langmuir adsorption isotherm. Yadav et al. [16] discussed the inhibition performance of two acetohydrazide derivatives on mild steel in $15 \% \mathrm{HCl}$. Both the derivatives showed more than $90 \%$ inhibition efficiency at $400 \mathrm{ppm}$.

This work aims at investigating the corrosion inhibition behaviour of $N$-[(3,4-dimethoxyphenyl) methyleneamino]4-hydroxy-benzamide (DMHB) on MS in $0.5 \mathrm{M} \mathrm{H}_{2} \mathrm{SO}_{4}$ (of $\mathrm{pH} 0.29$ ) and $0.5 \mathrm{M} \mathrm{HCl}$ (of $\mathrm{pH} 0.3$ ) using electrochemical techniques. DMHB is basically a Schiff base compound obtained by the simple condensation of aromatic aldehyde and benzo-fused hydrazide. It includes an imine group (containing $\pi$ electrons and lone pair of electrons on the nitrogen atom), two phenyl units and electron-rich oxygen atoms in the moiety. The presence of two electron donating methoxy groups, one hydroxyl and carbonyl group play a significant role in enhancing the inhibition efficiency of DMHB, which is further compared with structurally similar reported compounds. The activation and thermodynamic parameters were calculated for the dissolution process (corrosion) and adsorption process (protection), respectively. SEM and AFM were carried out for the MS coupons exposed to acids with and without the inhibitor. DFT calculations were done and the values obtained were in agreement with the experimental results.

\section{Experimental Details}

\subsection{Material}

MS (skin rolled plain carbon steel) rod having composition (\%wt), C: (0.17); Si: (0.16); Mn: (0.41); P: (0.06); S: (0.05); $\mathrm{Cr}(0.02)$ and $\mathrm{Fe}$ (Balance) was used in this investigation. The cylindrical coupon of $1 \mathrm{~cm}^{2}$ area of cross section was prepared and it was mounted using cold setting resin. The exposed flat surface of the mounted sample was disc polished with levigated alumina as per standard metallographic practice.

\subsection{Preparation of DMHB}

The inhibitor $N^{\prime}$-(3,4-dimethoxybenzylidene)-4-hydroxybenzohydrazide (DMHB) was synthesized as per the reported procedure [24] and characterized using ${ }^{1} \mathrm{H}$ NMR spectroscopic technique. The synthetic route for the preparation of DMHB is given in scheme 1. 
Scheme 1 Synthetic route for DMHB

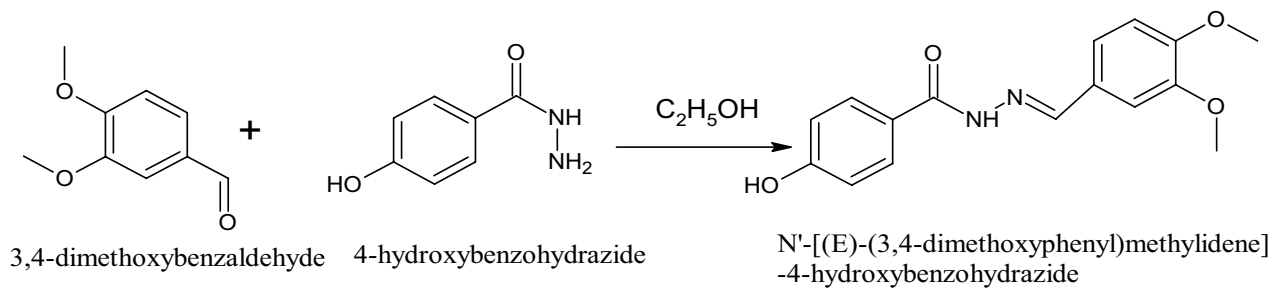

\subsection{Preparation of Medium}

The AnalaR Grade acids (Merck) and distilled water were used for the preparation of the aggressive solutions. $0.5 \mathrm{M}$ $\mathrm{HCl}$ was prepared by using $\mathrm{HCl}(37 \%)$ and $0.5 \mathrm{M} \mathrm{H}_{2} \mathrm{SO}_{4}$ prepared using $\mathrm{H}_{2} \mathrm{SO}_{4}(98 \%)$. DMHB inhibitor solution of $5 \mathrm{mM}$ was first prepared by dissolving the calculated quantity of the DMHB separately in $0.5 \mathrm{M} \mathrm{HCl}$ and $0.5 \mathrm{M} \mathrm{H}_{2} \mathrm{SO}_{4}$ solution. The required concentration of inhibitor solutions was then prepared by dilution method using prepared acids.

\subsection{Electrochemical Measurements}

Since corrosion is an electrochemical process, electrochemical methods of determination of corrosion rates are adopted. Potentiodynamic polarization (PDP) and electrochemical impedance spectroscopy (EIS) studies were done using electrochemical workstation with beta software. The corrosion study cell consisted of saturated calomel electrode (reference electrode), platinum electrode (counter electrode) and working electrode, i.e. MS as mounted sample. The PDP studies were conducted by measuring the current continuously by altering the potential of the metal from $-0.25 \mathrm{~V}$ cathodic to $+0.25 \mathrm{~V}$ anodic with respect to open-circuit potential (OCP) with a scan rate of $0.001 \mathrm{Vsec}^{-1}$. Extrapolating the linear portion of cathodic and anodic polarization curves in the potential versus log (current density) to meet at the intersection point corresponding to corrosion potential $\left(E_{\text {corr }}\right)$ and corrosion current density $\left(i_{\text {corr }}\right)$. Corrosion rate was calculated using Eq. (1) given below [24].

$\mathrm{CR}\left(\mathrm{mmy}^{-1}\right)=\frac{3270 \times E W \times i_{\text {corr }}}{d}$.

The constant, 3270 , indicates the conversion unit, $i_{\text {corr }}$ is corrosion current density in $\mathrm{A} \mathrm{cm}^{-2}, d$ is the density of the corroding metal $\left(7.725 \mathrm{~g} \mathrm{~cm}^{-3}\right)$, and $\mathrm{EW}$ (equivalent weight) equal to $M / Z$ where $M$ is atomic mass of the metal (55.85) and $Z$ is the number of electron transferred per metal atom $(Z=2)$. The percentage inhibition efficiency (\% IE) of the compound and surface coverage on the metal surface by the inhibitor $(\theta)$ are calculated using Eqs. (2) and (3), respectively.
$\mathrm{IE}(\%)=\frac{i_{\text {corr }}-i_{\text {corr(inh) }}}{i_{\text {corr }}} \times 100$

where $i_{\text {corr }}$ represents the corrosion current density in uninhibited solution and $i_{\text {corr (inh) }}$ is in the inhibited condition [25].

$\theta=\frac{I E(\%)}{100}$.

In Electrochemical impedance spectroscopy studies, the frequency ranges of $100 \mathrm{kHz}$ to $0.01 \mathrm{~Hz}$ and small amplitude AC signal of $10 \mathrm{mV}$ at the OCP were applied. The real (resistance) and imaginary (capacitance) components of the impedance response of the system were recorded by the EIS instrument. Depending upon the shape of the EIS spectrum, different circuit models were tried to fit in for the Nyquist plot using ZSimpWin software of version 3.21.

The \% IE is calculated using Eq. (4).

$\% \mathrm{IE}=\frac{R_{\mathrm{ct}(\mathrm{inh})}-R_{\mathrm{ct}}}{R_{\mathrm{ct}(\mathrm{inh})}} \times 100$,

where $R_{\mathrm{ct}(\mathrm{inh})}$ and $R_{\mathrm{ct}}$ are the charge-transfer resistances obtained under condition of inhibited and uninhibited solution, respectively [26].

The double-layer capacitance $\left(C_{\mathrm{dl}}\right)$ was calculated using Eq. (5).

$C_{\mathrm{dl}}=\frac{1}{2 \pi R_{\mathrm{ct}} f_{\max }}$,

where $f_{\max }$ is the frequency at the top of the semicircle (where- $Z$ ' is maximum).

\subsection{Surface Characterization}

The SEM and AFM images were recorded using analytical scanning electron microscope (JEOL JSM-6380 L) model and 1B342 Innova model, respectively. The polished MS specimen was first dipped in acid solution for about $3 \mathrm{~h}$, then gently washed with distilled water, and dried and its SEM and AFM images were taken. Similarly, the above procedure was then repeated with MS specimen immersed in acid medium with DMHB. 


\subsection{Quantum Chemical Study}

Corrosion inhibition effectiveness is dependent on the molecular structure of the inhibitor. The quantum chemical parameters of DMHB were evaluated using Gaussian maestro material science software with the correlation factor (B3LYP) and $631+\mathrm{G}$ as basis set [27]. DFT calculations were used to arrive at the optimized structure of DMHB with definite highest and lowest occupied molecular orbital levels.

\section{Results and Discussion}

\subsection{Characterization of DMHB}

Characterization of inhibitor compound was done by recording $\mathrm{H}^{1} \mathrm{NMR}$ spectra of DMHB.

Molecular formula: $\mathrm{C}_{16} \mathrm{H}_{16} \mathrm{~N}_{2} \mathrm{O}_{4}$.

${ }^{1} \mathrm{H}$ NMR: $\delta=3.38\left(\mathrm{~d}, 6 \mathrm{H}, \mathrm{OCH}_{3}\right), \delta=11.512(\mathrm{~s}, 1 \mathrm{H}, \mathrm{OH})$, $\delta=10.097(\mathrm{~s}, 1 \mathrm{H}, \mathrm{NH}), \delta=8.351(\mathrm{CH}=\mathrm{N}), \delta=6.8-7.8($ Ar. $\mathrm{CH})$. Fig. 1 represents the ${ }^{1} \mathrm{H}$ NMR spectrum of DMHB molecule.

\subsection{Potentiodynamic Polarization Studies}

The Tafel polarization technique was used in studying the rate of corrosion of MS in acid media and role of the inhibition effect of DMHB. The dissolution of the MS in $0.5 \mathrm{M} \mathrm{H}_{2} \mathrm{SO}_{4}$ and $0.5 \mathrm{M} \mathrm{HCl}$ solution at 303 and $323 \mathrm{~K}$ with and without the inhibitor DMHB is shown by the Tafel polarization curves in Fig. 2a, b respectively. Eqs. (1), (2) and (3) were used to calculate CR, \% IE and $\theta$ [28].

Electrochemical corrosion kinetic parameters such as $E_{\text {corr }}, i_{\text {corr }}, \%$ IE, cathodic slope $\left(\beta_{\mathrm{c}}\right)$, anodic slope $\left(\beta_{\mathrm{a}}\right)$ and $\mathrm{CR}$ are obtained for $0.5 \mathrm{M} \mathrm{H}_{2} \mathrm{SO}_{4}$ and $0.5 \mathrm{M} \mathrm{HCl}$ and given in Tables 1 and 2. From the tables, it is seen that in the absence of DMHB, the CR increases with increase in temperature due to increase in the conductance of the medium as well higher dissolution of metal because of overcoming the binding energy. Addition of DMHB resulted in an increase in \% IE which is due to its blockading effect, i.e. bonding interaction with the MS surface due to greater electron density present at active functional groups in DMHB. In the present study, the maximum inhibition efficiency obtained is $86 \%$ in $0.5 \mathrm{M} \mathrm{H}_{2} \mathrm{SO}_{4}$ and $81 \%$ in $0.5 \mathrm{M} \mathrm{HCl}$ at $303 \mathrm{~K}$. For the same concentration $\left(3 \times 10^{-3}\right) \mathrm{M}$ of inhibitor, the \% IE of DMHB was more in $0.5 \mathrm{M} \mathrm{H}_{2} \mathrm{SO}_{4}$. This may be due to the fact that $\mathrm{H}_{2} \mathrm{SO}_{4}$ with two protons will stimulate the constituents of DMHB to the greater extent than $\mathrm{HCl}$ and helps DMHB to adsorb to a greater extent. Though $\mathrm{H}_{2} \mathrm{SO}_{4}$ is a dibasic acid, $\mathrm{pH}$ of $0.5 \mathrm{M} \mathrm{H}_{2} \mathrm{SO}_{4}$ is 0.29 which is almost equal to that of $0.5 \mathrm{M} \mathrm{HCl}(\mathrm{pH} 0.3)$. Besides the surface damaging nature of $\mathrm{Cl}^{-}$causing the desorption of inhibitor molecules is

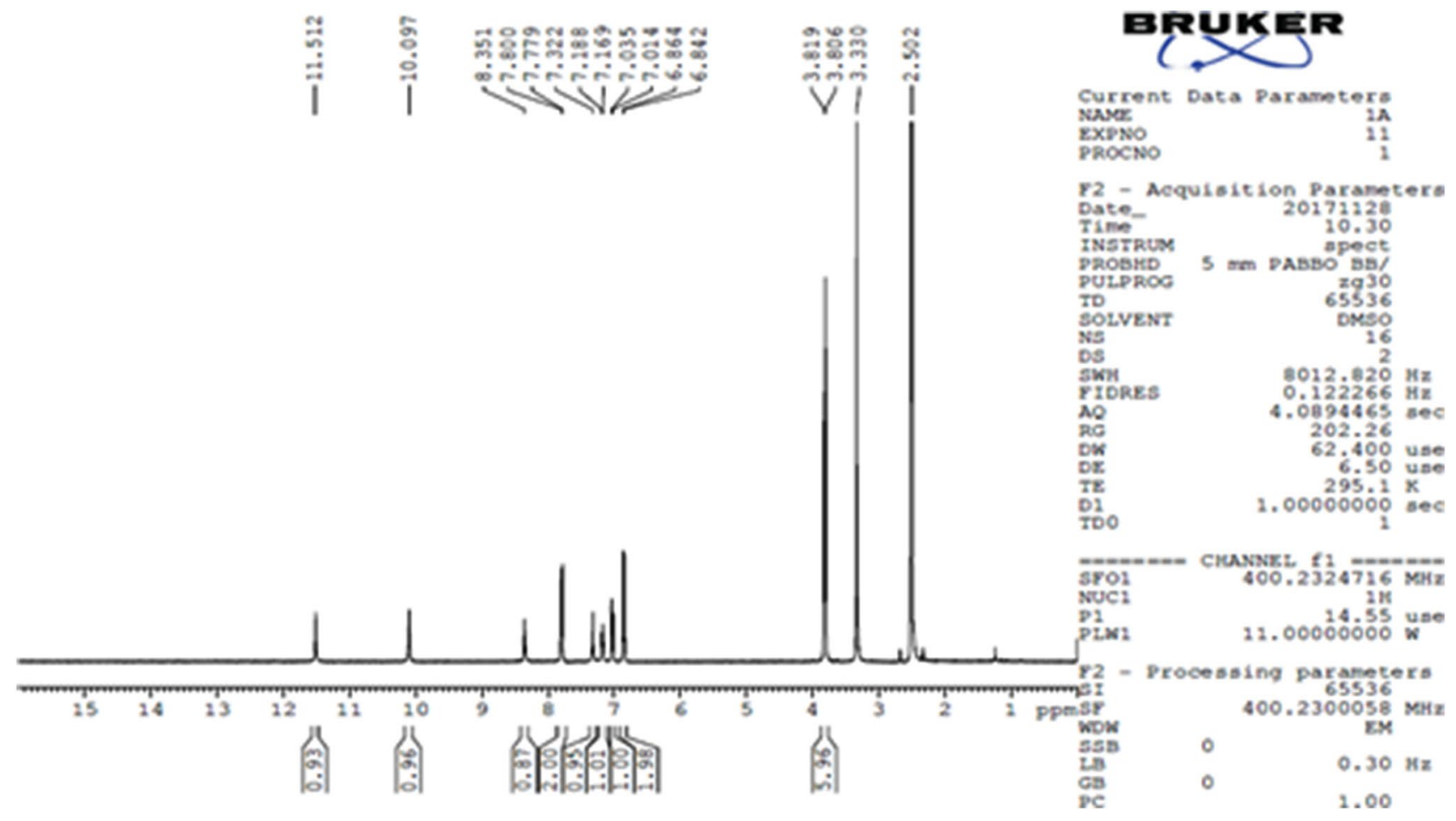

Fig. $1{ }^{1} \mathrm{H}$ NMR spectrum of DMHB 

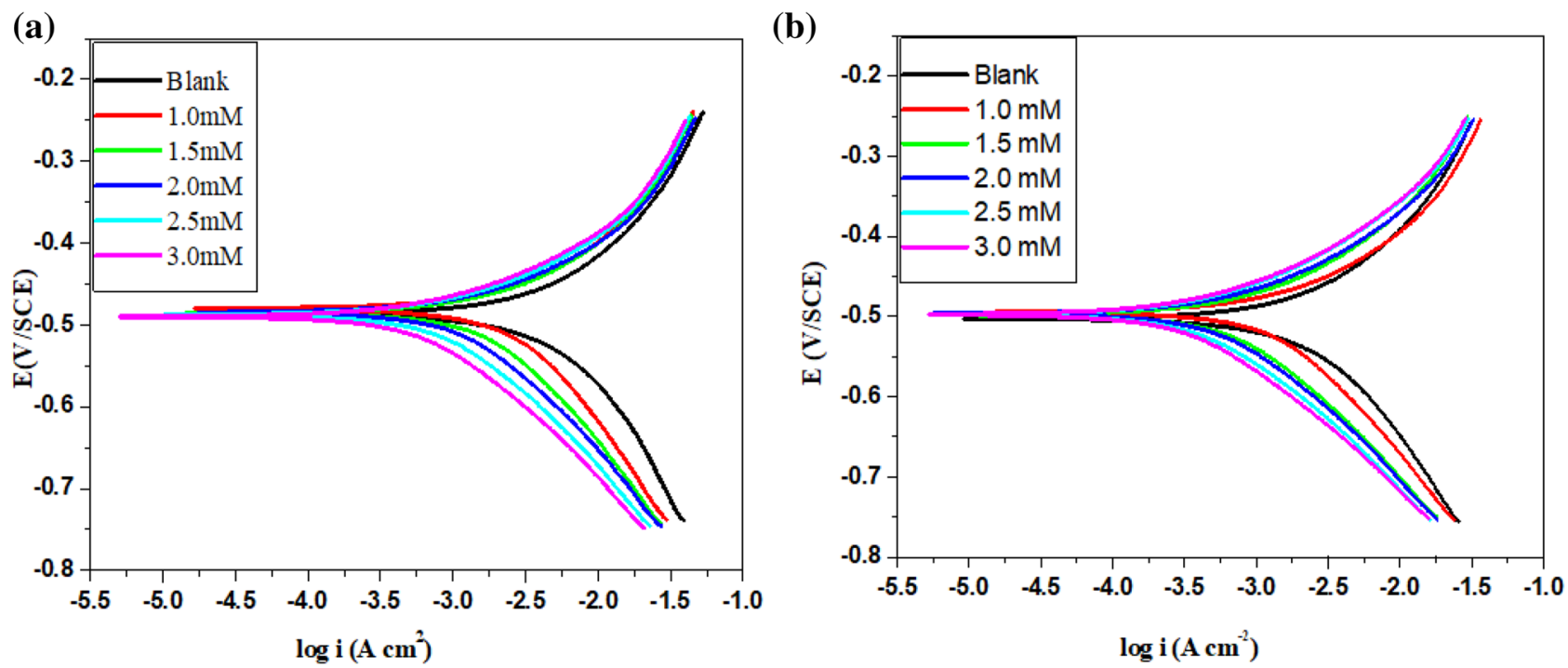

Fig. 2 PDP curves for mild steel with varying concentrations of DMHB a $0.5 \mathrm{M} \mathrm{H}_{2} \mathrm{SO}_{4}$ at $313 \mathrm{~K}$ and b $0.5 \mathrm{M} \mathrm{HCl}$ at $303 \mathrm{~K}$

Table 1 PDP results for mild steel corrosion in $0.5 \mathrm{M} \mathrm{H}_{2} \mathrm{SO}_{4}$ with and without the inhibitor DMHB at different temperatures

\begin{tabular}{|c|c|c|c|c|c|c|c|}
\hline Temp (K) & $\begin{array}{l}\text { Conc. DMHB } \\
10^{-3}(\mathrm{M})\end{array}$ & $E_{\text {corr }}(\mathrm{mV} / \mathrm{SCE})$ & $-\beta_{c}(\mathrm{mV} / \mathrm{dec})$ & $\beta_{a}(\mathrm{mV} / \mathrm{dec})$ & $i_{\text {corr }}\left(\mathrm{mAcm}^{-2}\right)$ & $C R\left(\mathrm{mmy}^{-1}\right)$ & $\%$ IE \\
\hline \multirow[t]{6}{*}{303} & 0 & -499 & 4.949 & 5.875 & 3.055 & 18.04 & 0 \\
\hline & 1.0 & -498 & 5.593 & 7.036 & 1.956 & 11.55 & 35.97 \\
\hline & 1.5 & -490 & 6.288 & 8.451 & 1.082 & 6.39 & 64.58 \\
\hline & 2.0 & -490 & 6.876 & 9.307 & 0.723 & 4.27 & 76.33 \\
\hline & 2.5 & -492 & 7.223 & 9.934 & 0.487 & 2.88 & 84.06 \\
\hline & 3.0 & -489 & 7.609 & 20.592 & 0.480 & 2.41 & 86.0 \\
\hline \multirow[t]{6}{*}{313} & 0 & -487 & 5.203 & 6.227 & 4.663 & 27.55 & 0 \\
\hline & 1.0 & -488 & 5.050 & 6.715 & 3.184 & 18.80 & 31.72 \\
\hline & 1.5 & -485 & 5.751 & 7.336 & 2.277 & 13.44 & 51.17 \\
\hline & 2.0 & -485 & 6.415 & 8.329 & 1.542 & 9.11 & 66.93 \\
\hline & 2.5 & -488 & 6.766 & 8.835 & 1.059 & 6.25 & 77.29 \\
\hline & 3.0 & -490 & 7.149 & 9.591 & 0.757 & 4.47 & 83.77 \\
\hline \multirow[t]{6}{*}{323} & 0 & -480 & 5.141 & 5.701 & 6.173 & 36.47 & 0 \\
\hline & 1.0 & -477 & 5.050 & 6.269 & 4.362 & 29.41 & 19.0 \\
\hline & 1.5 & -478 & 5.172 & 6.513 & 3.461 & 25.75 & 29.0 \\
\hline & 2.0 & -480 & 5.772 & 6.863 & 3.235 & 19.11 & 47.59 \\
\hline & 2.5 & -481 & 6.325 & 7.312 & 2.333 & 13.782 & 62.21 \\
\hline & 3.0 & -483 & 6.451 & 7.564 & 1.944 & 11.485 & 68.51 \\
\hline
\end{tabular}

more than that of $\mathrm{SO}_{4}{ }^{2-}$. Since the maximum displacement in $E_{\text {corr }}$ is found to be less than $\pm 20 \mathrm{mV}$, DMHB acts as mixed type of inhibitor affecting both hydrogen evolution and metal dissolution to the same extent [28, 29]. Further, there is not much variation observed in the values of $\beta_{\mathrm{c}}$ and $\beta_{\mathrm{a}}$ in the absence and presence of DMHB. This suggests that the mechanism of corrosion and its inhibitive action remains unchanged [30].

\subsection{Evaluation of Kinetic Parameters}

Usually, the corrosion rate increases with the increase in temperature in all corrosive medium and especially in acid medium the over potential decreases due to the evolution of hydrogen [31]. From Tables 1 and 2, it is seen that with the increase in temperature, inhibition efficiency decreases in both $0.5 \mathrm{M} \mathrm{H}_{2} \mathrm{SO}_{4}$ and $0.5 \mathrm{M} \mathrm{HCl}$. This is 
Table 2 PDP results for mild steel corrosion in $0.5 \mathrm{M} \mathrm{HCl}$ with and without the inhibitor DMHB at different temperatures

\begin{tabular}{|c|c|c|c|c|c|c|c|}
\hline Temp (K) & $\begin{array}{l}\text { DMHB Conc. } \\
10^{-3}(\mathrm{M})\end{array}$ & $E_{\text {corr }}(\mathrm{mV} / \mathrm{SCE})$ & $-\beta_{c}(\mathrm{mV} / \mathrm{dec})$ & $\beta_{a}(\mathrm{mV} / \mathrm{dec})$ & $i_{\text {corr }}\left(\mathrm{mAcm}^{-2}\right)$ & $\mathrm{CR}\left(\mathrm{mmy}^{-1}\right)$ & $\% \mathrm{IE}$ \\
\hline \multirow[t]{6}{*}{303} & 0 & -503 & 5.515 & 6.679 & 2.192 & 12.94 & - \\
\hline & 1.0 & -493 & 5.809 & 7.594 & 1.680 & 9.926 & 23.36 \\
\hline & 1.5 & -498 & 6.671 & 8.071 & 0.860 & 5.081 & 60.77 \\
\hline & 2.0 & -496 & 7.089 & 8.888 & 0.667 & 3.944 & 69.57 \\
\hline & 2.5 & -497 & 7.511 & 9.220 & 0.469 & 2.771 & 78.60 \\
\hline & 3.0 & -497 & 7.686 & 9.408 & 0.404 & 2.388 & 81.57 \\
\hline \multirow[t]{6}{*}{313} & 0 & -498 & 5.577 & 6.261 & 3.073 & 18.15 & - \\
\hline & 1.0 & -494 & 5.797 & 7.039 & 2.159 & 12.75 & 29.74 \\
\hline & 1.5 & -494 & 6.084 & 7.301 & 1.359 & 8.028 & 55.78 \\
\hline & 2.0 & -497 & 6.530 & 8.329 & 1.098 & 6.487 & 64.27 \\
\hline & 2.5 & -494 & 6.907 & 8.520 & 0.9855 & 5.821 & 67.93 \\
\hline & 3.0 & -499 & 7.138 & 8.859 & 0.7073 & 4.178 & 76.98 \\
\hline \multirow[t]{6}{*}{323} & 0 & -488 & 5.108 & 5.899 & 5.091 & 30.07 & - \\
\hline & 1.0 & -495 & 5.381 & 6.410 & 4.165 & 24.60 & 18.19 \\
\hline & 1.5 & -488 & 5.633 & 7.063 & 2.764 & 16.33 & 45.71 \\
\hline & 2.0 & -493 & 5.782 & 7.014 & 2.480 & 14.65 & 51.29 \\
\hline & 2.5 & -498 & 6.293 & 6.293 & 2.273 & 13.42 & 55.35 \\
\hline & 3.0 & -493 & 7.941 & 7.941 & 1.636 & 9.66 & 67.86 \\
\hline
\end{tabular}

because at increased temperature, dissolution rate of the metal is high and there is the possibility of desorption of the adsorbed inhibitor molecules from the metal surface. Arrhenius equation (Eq. (6)) was used for calculation of the activation energy $\left(E_{\mathrm{a}}\right)$ from corrosion rate of MS in the acid medium [32]. $\ln (C R)=B-\frac{E_{a}}{R T}$,

where $B$ is Arrhenius pre-exponential constant, $T$ is temperature and $R$ is universal gas constant.

Figure $3 \mathrm{a}, \mathrm{b}$ is the Arrhenius plot of $\ln (C R) \mathrm{v} / \mathrm{s} 1 / T$ and from this straight line graph, the slope $\left(E_{\mathrm{a}} / R\right)$ was obtained. From the slope, the activation energy was calculated. According to Bentiss et al. [33] and Hegazy et al. [34], (a)

(b)

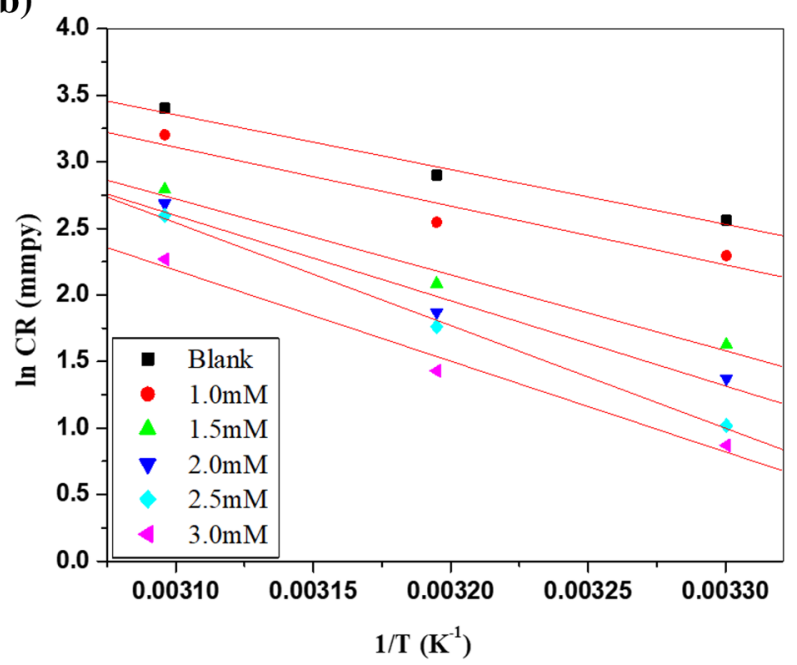

(a)

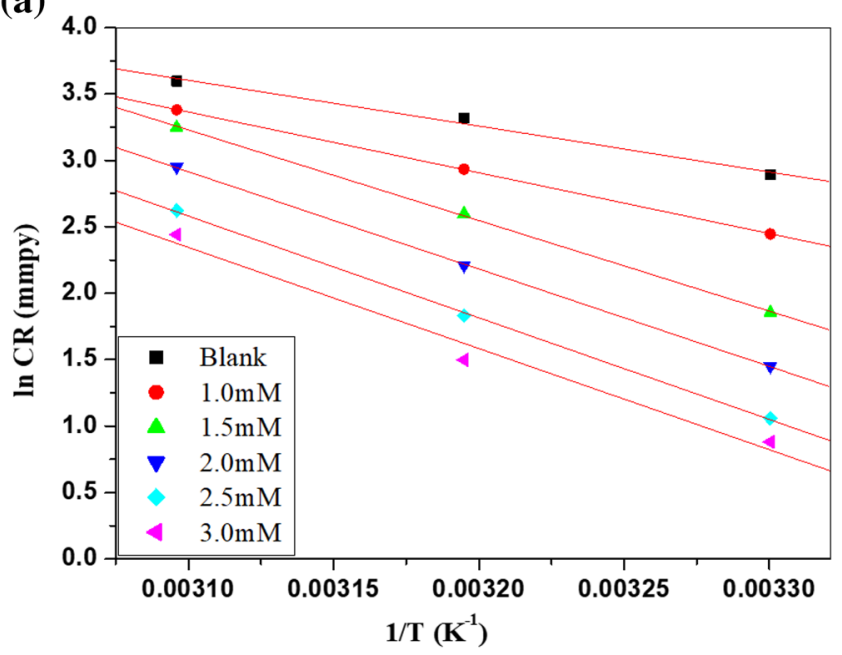

Fig. 3 Arrhenius plot of $\ln (\mathrm{CR}) \mathrm{v} / \mathrm{s}(1 / \mathrm{T})$ for mild steel in a $0.5 \mathrm{M} \mathrm{H}_{2} \mathrm{SO}_{4}$ and $\mathbf{b} 0.5 \mathrm{M} \mathrm{HCl}$ solutions with varying concentrations of DMHB 
if inhibition efficiency of inhibitor increases with increase in the temperature, then the energy of activation is smaller for inhibited solution in comparison with uninhibited solution. (b) If there is no change in the inhibition efficiency of inhibitor, then energy of activation values remains constant. (c) If inhibition efficiency of inhibitor decreases with increase in the temperature, then the energy of activation is higher for inhibited solution in comparison with uninhibited solution. The $E_{\mathrm{a}}$ values obtained for $0.5 \mathrm{M} \mathrm{H}_{2} \mathrm{SO}_{4}$ and $0.5 \mathrm{M} \mathrm{HCl}$ are given in Table 3. In both the acid solutions, in the presence of DMHB, the $E_{\mathrm{a}}$ values are greater than in its absence. The increase is proportional to the inhibitor concentration which indicates the increase in the energy barrier for corrosion reaction. [29].

The enthalpy and entropy of activation for metal dissolution is evaluated using the transition state equation:

$C R=\frac{R T}{N h} \exp \left(\frac{\Delta S^{\#}}{R T}\right) \exp \left(\frac{-\Delta H^{\#}}{R T}\right)$,

where $h$ is Planck's constant and $N$ is Avogadro's number. Plot of $\ln (C R / T) \mathrm{v} / \mathrm{s} 1 / T$ shown in Fig. $4 \mathrm{a}$, b gives a straight line with slope $\frac{-\Delta H^{\#}}{R T}$ and intercept $\ln (R / N h)+\left(\Delta S^{\#} / R\right)$. With increase in inhibitor concentration, the activation energy increases indicating that adsorption of DMHB takes place. The negative values of entropy $\left(\Delta S^{\#}\right)$ imply that there is a decrease in randomness in moving from the reactants to the activated complex [35].

Thermodynamic calculations are helpful to understand the feasibility of corrosion process. The tendency of the material to corrode depends upon the energy associated with the chemical reaction occurring during the corrosion process [36]. The data obtained for $\theta$ were fitted into different adsorption isotherms and the best fit was for Langmuir adsorption. Fig. 5a, b shows linear plots of $C_{i n h} / \theta \mathrm{v} / \mathrm{s} C_{\text {inh }}$ for both $0.5 \mathrm{M} \mathrm{H}_{2} \mathrm{SO}_{4}$ and $0.5 \mathrm{M} \mathrm{HCl}$. The Langmuir equation assumes that the adsorption reaction involves the formation of unimolecular layer with a constant energy of adsorption. Langmuir isotherm points to homogeneous adsorption over the metal surface, wherein the inhibitor molecule has constant enthalpies and adsorption activation energy [37].
Table 3 Activation parameters for the corrosion of mild steel in $0.5 \mathrm{M} \mathrm{H}_{2} \mathrm{SO}_{4}$ and $0.5 \mathrm{M} \mathrm{HCl}$ solutions containing different amounts of DMHB

\begin{tabular}{|c|c|c|c|c|c|c|}
\hline \multirow[b]{2}{*}{$\begin{array}{l}\text { Conc. } \\
\text { DMHB } \\
10^{-3}(\mathrm{M})\end{array}$} & \multicolumn{3}{|l|}{$0.5 \mathrm{M} \mathrm{H}_{2} \mathrm{SO}_{4}$} & \multicolumn{3}{|l|}{$0.5 \mathrm{M} \mathrm{HCl}$} \\
\hline & $E_{a}\left(\mathrm{kJmol}^{-1}\right)$ & $\Delta H^{\ddagger}\left(\mathrm{kJmol}^{-1}\right)$ & $\begin{array}{l}-\Delta S^{\ddagger} \\
\left(\mathrm{Jmol}^{-1} \mathrm{~K}^{-1}\right)\end{array}$ & $\overline{E_{a}\left(\mathrm{kJmol}^{-1}\right)}$ & $\Delta H^{ \pm}\left(\mathrm{kJmol}^{-1}\right)$ & $\begin{array}{l}-\Delta S^{\ddagger} \\
\left(\mathrm{Jmol}^{-1} \mathrm{~K}^{-1}\right)\end{array}$ \\
\hline 0 & 34.19 & 31.59 & 119.7 & 28.67 & 26.07 & 134.7 \\
\hline 1.0 & 36.74 & 34.14 & 113.8 & 38.02 & 35.42 & 107.7 \\
\hline 1.5 & 47.38 & 44.78 & 84.10 & 56.71 & 54.11 & 50.95 \\
\hline 2.0 & 53.22 & 50.62 & 67.01 & 60.93 & 58.33 & 40.47 \\
\hline 2.5 & 64.14 & 61.54 & 33.64 & 63.66 & 61.06 & 34.80 \\
\hline 3.0 & 56.72 & 54.12 & 59.60 & 63.31 & 60.71 & 37.84 \\
\hline
\end{tabular}
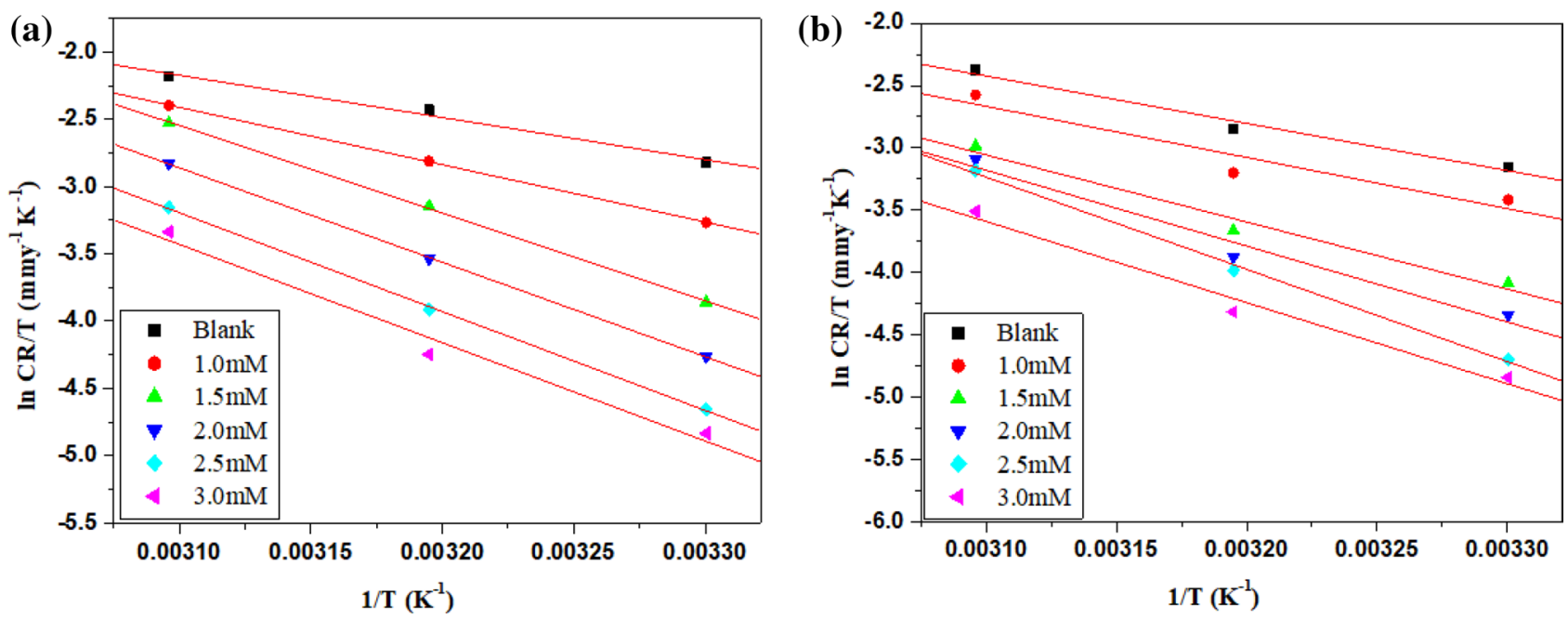

Fig. 4 Plot of $\ln (\mathrm{CR} / \mathrm{T}) \mathrm{v} / \mathrm{s} 1 / \mathrm{T}$ for mild steel in a $0.5 \mathrm{M} \mathrm{H}_{2} \mathrm{SO}_{4}$ and $\mathbf{b} 0.5 \mathrm{M} \mathrm{HCl}$ solutions with varying DMHB concentrations 
(a)

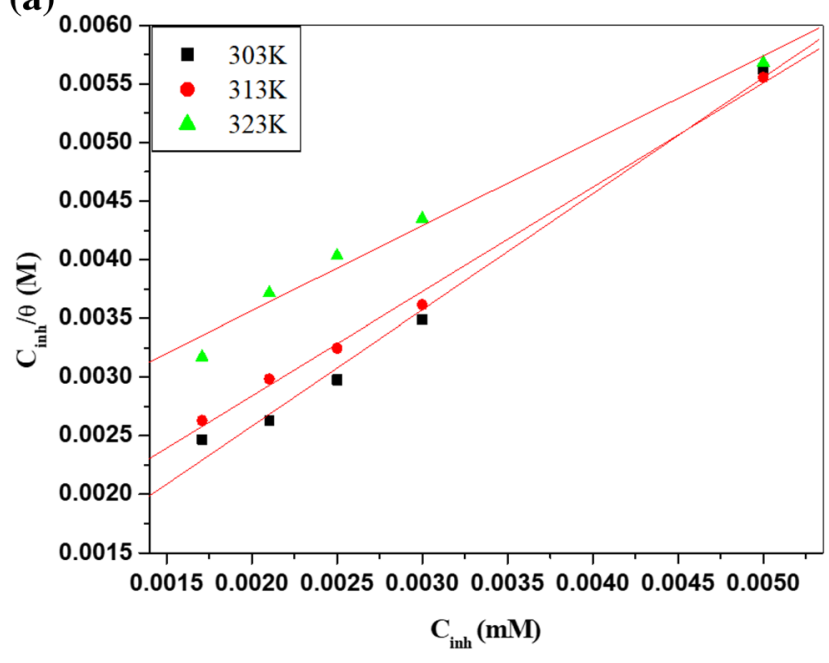

(b)

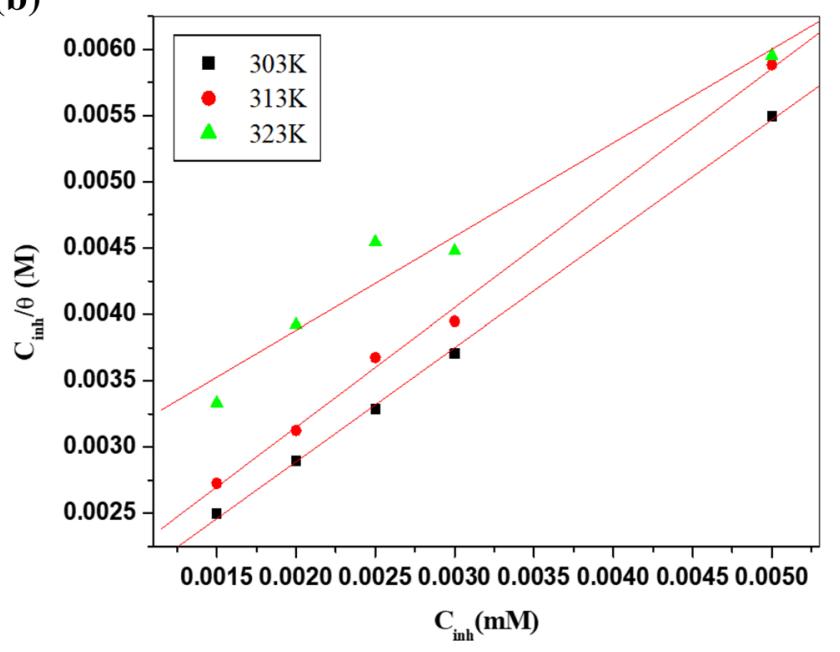

Fig. 5 Langmuir adsorption isotherm of mild steel in a $0.5 \mathrm{M} \mathrm{H}_{2} \mathrm{SO}_{4}$ and $\mathbf{b} 0.5 \mathrm{M} \mathrm{HCl}$ solutions

The conventional form of the Langmuir isotherm is expressed as in Eq. (8):

$\frac{C_{\mathrm{inh}}}{\theta}=\frac{1}{K}+C_{\mathrm{inh}}$

where the concentration of inhibitor is $C_{\text {inh }}$ and $K_{\text {ads }}$ is the equilibrium constant for adsorption process and these are obtained from the inverse of Langmuir's plot. The values of $K_{\text {ads }}$ indicate that a stable adsorbed layer is formed on the surface of the metal. It also represents the strength between adsorbate and adsorbent. Larger values of $K_{\text {ads }}$ indicate efficient adsorption and hence better inhibition efficiency. In the present study, $K_{\text {ads }}$ values decreased with increase in the temperature suggesting that adsorption of DMHB on MS surface was not favourable at higher temperature [38, 39]. The small deviations in the curve might be because of the interaction of the adsorbed species replacing the water molecules that were previously adsorbed.

The standard free energy change of adsorption $\left(\Delta G_{\text {ads }}^{\circ}\right)$ is related to the $K_{\text {ads }}$ by the relation:
$K=\frac{1}{55.5} \exp \left(\frac{-\Delta G_{\mathrm{ads}}^{\circ}}{R T}\right)$

where $R$ is universal gas constant, and $T$ is absolute temperature. 55.5 is the concentration of water in solution in mol $\mathrm{dm}^{-3}$. Table 4 gives the thermodynamic parameters derived from Langmuir adsorption isotherms for the studied compound. The negative values of $\Delta G^{\circ}$ ads show the adsorption process is spontaneous and the adsorbed layer is stable [40].

Plot of $\Delta G^{\circ}{ }_{a d s}$ v/s $T$ is shown in Fig. 6a, b. Entropy of adsorption $\left(\Delta S^{\circ}{ }_{\text {ads }}\right)$ and enthalpy of adsorption $\left(\Delta H^{\circ}\right.$ ads $)$ are the adsorption parameters that can be obtained from the slope and the intercept of the graph using Eq. (10):

$\Delta G_{\mathrm{ads}}^{\mathrm{o}}=\Delta \mathrm{H}_{\mathrm{ads}}^{\mathrm{o}}-T \Delta S_{\mathrm{ads}}^{\mathrm{o}}$.

Generally, the $\Delta G_{\text {ads }}^{\circ}$ values of $-20 \mathrm{~kJ} \mathrm{~mol}^{-1}$ or less negative are associated with physisorption and those with $-40 \mathrm{~kJ} \mathrm{~mol}^{-1}$ or more negative involve chemisorption [41].

The $\Delta G_{a d s}^{\circ}$ values for the DMHB in $0.5 \mathrm{M} \mathrm{H}_{2} \mathrm{SO}_{4}$ and $0.5 \mathrm{M} \mathrm{HCl}$ lie between -20 and $-40 \mathrm{~kJ} \mathrm{~mol}^{-1}$. The negative values of $\Delta H^{\circ}$ ads suggest that the adsorption of inhibitor on
Table 4 Thermodynamic parameters for the corrosion of mild steel in $0.5 \mathrm{M} \mathrm{H}_{2} \mathrm{SO}_{4}$ and $0.5 \mathrm{M} \mathrm{HCl}$ solutions containing different amounts of DMHB

\begin{tabular}{lllllll}
\hline Medium & Temp. (K) & $K_{\text {ads }}$ & $\begin{array}{l}-\Delta G^{\mathrm{o}}(\mathrm{kJ} \\
\left.\mathrm{mol}^{-1}\right)\end{array}$ & $R^{2}$ & $\begin{array}{c}-\Delta H^{\mathrm{o}}(\mathrm{kJ} \\
\left.\mathrm{mol}^{-1}\right)\end{array}$ & $\begin{array}{c}-\Delta S^{\mathrm{o}}(\mathrm{J} \text { ads } \\
\left.\mathrm{mol}^{-1} \mathrm{~K}^{-1}\right)\end{array}$ \\
\hline $0.5 \mathrm{M} \mathrm{H}_{2} \mathrm{SO}_{4}$ & 303 & 909 & 27.40 & 0.995 & 36.20 & 0.029 \\
& 313 & 666.6 & 27.11 & 0.997 & & \\
$0.5 \mathrm{M} \mathrm{HCl}$ & 323 & 374.5 & 26.82 & 0.992 & & 0.0108 \\
& 303 & 854.7 & 27.33 & 0.999 & 30.61 & \\
& 313 & 740.7 & 27.22 & 0.998 & & \\
\hline
\end{tabular}



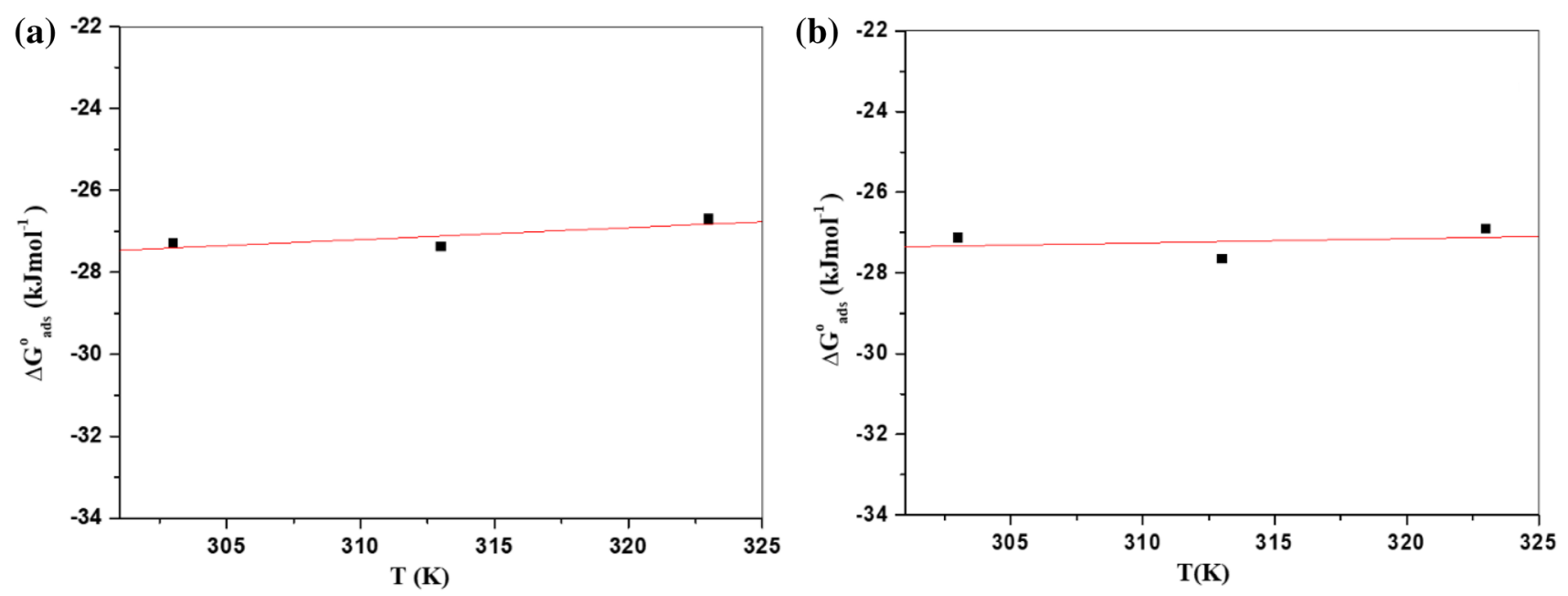

Fig. 6 Plot of $\Delta \mathrm{G}^{\circ}$ ads $\mathrm{v} / \mathrm{s} \mathrm{T}$ for the adsorption of mild steel in $\mathbf{a} 0.5 \mathrm{M} \mathrm{H}_{2} \mathrm{SO}_{4}$ and $\mathbf{b} 0.5 \mathrm{M} \mathrm{HCl}$ solutions

MS follows physisorption. The negative $\Delta S^{\circ}$ ads values in both $0.5 \mathrm{M} \mathrm{H}_{2} \mathrm{SO}_{4}$ and $0.5 \mathrm{M} \mathrm{HCl}$ indicate that decrease in randomness takes place on moving from the reactant to the adsorbed species [42].

\subsection{Electrochemical Impedance Spectroscopy (EIS) Studies}

The characteristic features and kinetics of the electrochemical reactions that occur at the interface of MS and acid media can be determined by EIS technique. The impedance responses of MS without and with different concentrations of DMHB at different temperature ranges in both acids separately were studied by EIS and are expressed in terms of Nyquist plot as shown in Fig. 7a, b. These plots are non-ideal and consist of depressed semicircles. The slight deviation from the perfect semicircle can be attributed to the inhomogeneity and impurities (other elements in ferrite phase) of the metal surface. Increase in concentration of DMHB increases the diameters of the semicircles in the Nyquist plots. This indicates that the addition of DMHB increases the corrosion resistance of the metal due to its adsorption [43].

The data obtained were fitted into the suitable equivalent circuit using the ZSimpWin software version 3.21. Figure 8 shows the equivalent circuit used for DMHB in $0.5 \mathrm{M}$ $\mathrm{H}_{2} \mathrm{SO}_{4}$. Similar circuit was used in case of $0.5 \mathrm{M} \mathrm{HCl}$. In the equivalent circuit, $R_{\mathrm{S}}$ represents the solution resistance, $R_{\mathrm{f}}$ represents the film resistance and $R_{\mathrm{ct}}$ represents the chargetransfer resistance. Among two constant phase elements
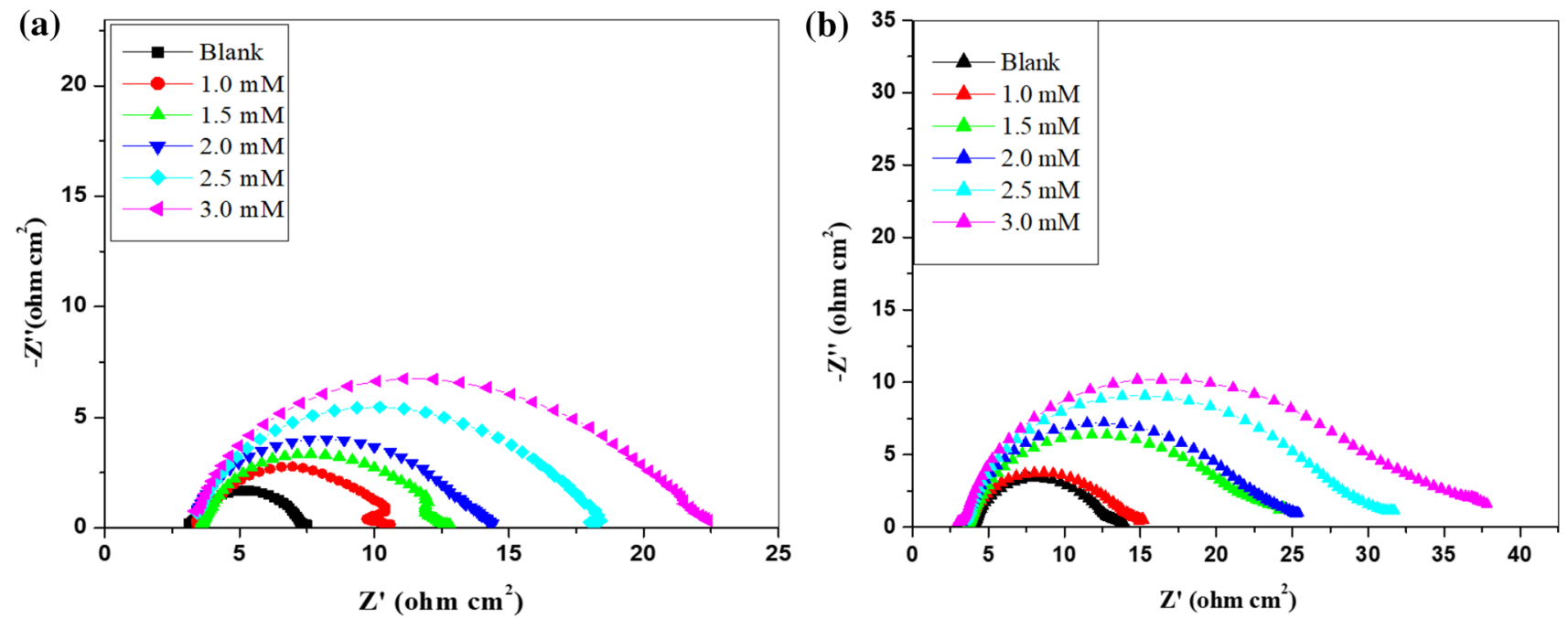

Fig. 7 Nyquist plots for the corrosion of $\mathrm{MS}$ in a $0.5 \mathrm{M} \mathrm{H}_{2} \mathrm{SO}_{4}$ at $313 \mathrm{~K}$ and $\mathbf{b} 0.5 \mathrm{M} \mathrm{HCl}$ at $303 \mathrm{~K}$ containing various concentrations of DMHB 


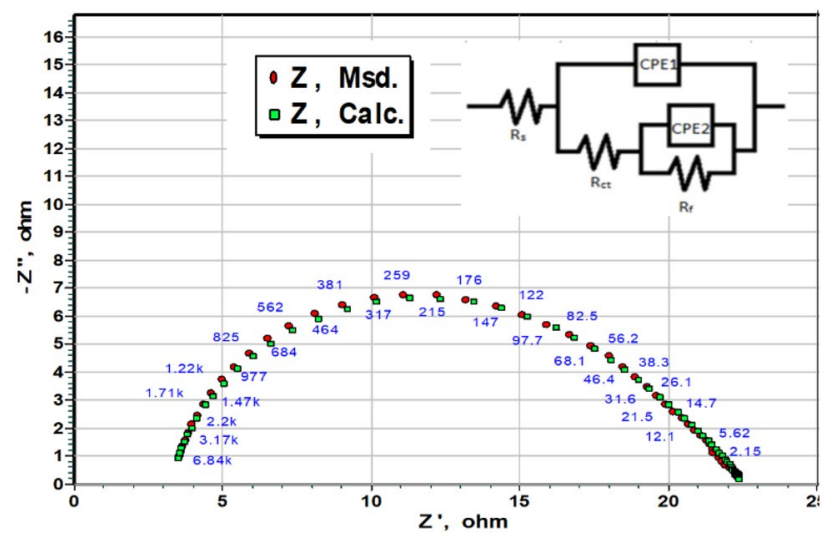

Fig. 8 Equivalent circuit fitment for the corrosion of MS in $0.5 \mathrm{M}$ $\mathrm{H}_{2} \mathrm{SO}_{4}$ containing $3 \times 10^{-3} \mathrm{M} \mathrm{DMHB}$ at $313 \mathrm{~K}$

(CPE), $\mathrm{CPE}_{1}$ denotes the time constant of the electrical double layer and $\mathrm{CPE}_{2}$ is the film capacitance. The CPE is introduced to compensate for the heterogeneity in the solution system. The CPE impedance is calculated using the following equation [44]:

$Z_{\mathrm{CPE}}=Q^{-1}\left(i w_{\max }\right)^{-n}$

where $Q$ represents the proportionality coefficient, $i w_{\max }$ the angular frequency with ' $i$ ' being the imaginary number and ' $\mathrm{n}$ ' is the exponent which is associated to the phase shift and its values lie between 0 and 1(i.e. $0 \leq n \leq 1$ ). The observed $\mathrm{n}$ values range from 0.81 to 0.9 suggesting the occurrence of little or no considerable roughness on the surface and also deviation of CPE from the ideal capacitive behaviour [45]. The \% IE and the disparity in the capacitance to its real value $\left(C_{\mathrm{dl}}\right)$ are calculated by using Eqs. (4) and (5), respectively.

The value of $R_{c t}$ is due to electron transfer across the metal surface and is inversely proportional to the corrosion rate. Table 5 shows that in the absence of the inhibitor the $R_{\mathrm{ct}}$ value is less as compared to the $R_{\mathrm{ct}}$ value in its presence. As the concentration of the DMHB increases, the $R_{\mathrm{ct}}$ values also increase and the $C_{\mathrm{dl}}$ values decrease. Decrease in the capacitance indicates the decrease in local dielectric constant and/or an increase in the thickness of the electrical double layer. This suggests that the inhibitor molecules get adsorbed at the metal/solution interface [46].

\subsection{Corrosion Inhibition Mechanism}

Factors such as nature of the metal, medium, $\mathrm{pH}$, inhibitor concentrations and the functional groups present in it decide the mechanism of adsorption. From the literature, it is known that $\mathrm{Cl}^{-}$ions can get easily adsorbed compared to $\mathrm{SO}_{4}{ }^{2-}$ ions [47]. The surface charge of the metal when in contact with the electrolyte can be determined by comparing the potential of zero charge (PZC) and the OCP of

Table 5 EIS results for mild steel corrosion in $0.5 \mathrm{M} \mathrm{H}_{2} \mathrm{SO}_{4}$ with and without the inhibitor DMHB at different temperatures

\begin{tabular}{|c|c|c|c|c|c|c|c|c|c|}
\hline \multirow[b]{2}{*}{ Temp. (K) } & \multicolumn{6}{|l|}{$0.5 \mathrm{M} \mathrm{H}_{2} \mathrm{SO}_{4}$} & \multicolumn{3}{|l|}{$0.5 \mathrm{M} \mathrm{HCl}$} \\
\hline & $\begin{array}{l}\text { Conc. DMHB } \\
10^{-3}(\mathrm{M})\end{array}$ & $R_{\mathrm{ct}}\left(\Omega \mathrm{cm}^{2}\right)$ & $C_{\mathrm{dl}}\left(\mu \mathrm{F} \mathrm{cm}^{-2}\right)$ & $n$ & $\%$ IE & $R_{\mathrm{ct}}\left(\Omega \mathrm{cm}^{2}\right)$ & $\left.\overline{C_{\mathrm{dl}}(\mu \mathrm{F} \mathrm{cm}} \mathrm{cm}^{-2}\right)$ & $n$ & $\%$ IE \\
\hline \multirow[t]{6}{*}{303} & 0 & 5.81 & 10,569 & 0.896 & - & 9.361 & 4977.28 & 0.925 & - \\
\hline & 1.0 & 9.64 & 3792.0 & 0.810 & 39.73 & 13.638 & 3095.40 & 0.912 & 31.36 \\
\hline & 1.5 & 16.29 & 1673.2 & 0.858 & 64.33 & 21.725 & 1151.54 & 0.819 & 56.91 \\
\hline & 2.0 & 22.43 & 902.75 & 0.874 & 74.09 & 26.501 & 832.45 & 0.892 & 64.68 \\
\hline & 2.5 & 30.09 & 523.44 & 0.843 & 80.69 & 33.679 & 522.26 & 0.829 & 72.2 \\
\hline & 3.0 & 32.91 & 423.31 & 0.851 & 82.34 & 38.971 & 400.99 & 0.816 & 75.98 \\
\hline \multirow[t]{6}{*}{313} & 0 & 4.271 & 22,152 & 0.813 & - & 10.254 & 5800.94 & 0.894 & - \\
\hline & 1.0 & 6.926 & 8202.2 & 0.791 & 38.33 & 13.673 & 3676.13 & 0.841 & 25.01 \\
\hline & 1.5 & 8.8 & 5420.8 & 0.889 & 51.4 & 25.241 & 1414.17 & 0.803 & 59.37 \\
\hline & 2.0 & 11.12 & 3533.12 & 0.899 & 61.59 & 27.371 & 1218.15 & 0.799 & 62.53 \\
\hline & 2.5 & 15.19 & 1912.94 & 0.825 & 71.88 & 29.732 & 1026.19 & 0.911 & 65.51 \\
\hline & 3.0 & 19.81 & 1185.91 & 0.728 & 78.44 & 40.648 & 607.54 & 0.889 & 74.77 \\
\hline \multirow[t]{6}{*}{323} & 0 & 2.431 & $64,725.4$ & 0.805 & - & 4.215 & $21,473.0$ & 0.869 & - \\
\hline & 1.0 & 3.068 & $30,711.3$ & 0.839 & 20.76 & 5.210 & $16,635.7$ & 0.823 & 19.1 \\
\hline & 1.5 & 3.587 & $21,803.7$ & 0.819 & 32.22 & 7.758 & 8249.73 & 0.777 & 45.66 \\
\hline & 2.0 & 4.369 & $15,023.3$ & 0.867 & 44.35 & 9.338 & 5720.37 & 0.807 & 54.86 \\
\hline & 2.5 & 7.152 & 7252.27 & 0.858 & 66.01 & 10.74 & 5091.48 & 0.925 & 60.75 \\
\hline & 3.0 & 8.497 & 5293.84 & 0.824 & 71.38 & 15.011 & 3015.33 & 0.847 & 71.92 \\
\hline
\end{tabular}


MS in the corresponding medium. The surface charge of the mild steel at OCP was found to be positive in the inhibited and uninhibited $0.5 \mathrm{M} \mathrm{HCl}$ and $0.5 \mathrm{M} \mathrm{H}_{2} \mathrm{SO}_{4}$ solutions with respect to PZC [48]. In acid media (i.e. $0.5 \mathrm{M} \mathrm{HCl}$ and $0.5 \mathrm{M} \mathrm{H}_{2} \mathrm{SO}_{4}$ ), the hydrazide derivatives get protonated and form positively charged species in the metal-solution interface. These positively charged inhibitor molecules cannot directly approach the positively charged metal surface due to electrostatic repulsive forces. However, the anions $\left(\mathrm{Cl}^{-}\right.$and $\mathrm{SO}_{4}{ }^{2-}$ ions) derived from the acids can directly get attached to the metal surface. Due to this, the chloride and sulphate ions are adsorbed first at the interface by electrostatic force of attraction. As a result of this, the charge of the solution side changes from positive to negative and the protonated inhibitor molecules are attracted towards the negative charge which facilitate the adsorption of DMHB. Thus, the protonated DMHB molecules will electrostatically adsorb on the

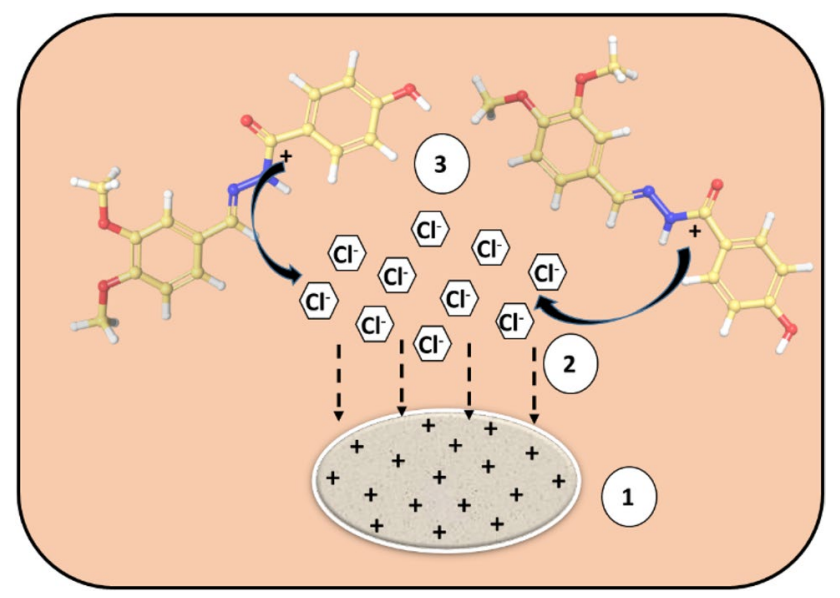

Fig. 9 A schematic representation of electrostatic interaction of protonated DMHB molecules on the MS surface

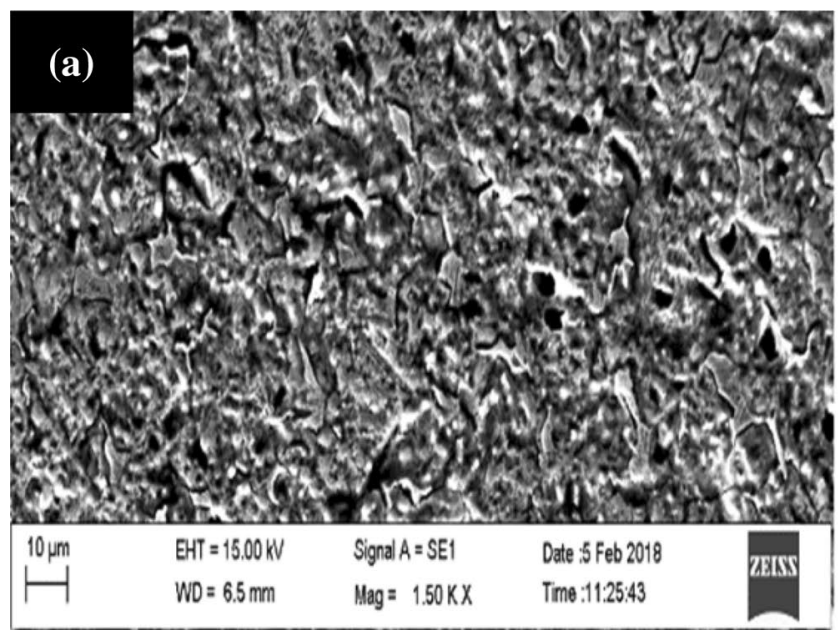

MS surface through the chloride and sulphate bridges leading to physisorption. These protonated DMHB molecules can also be adsorbed at the cathodic sites of the metal in competition with the hydrogen ions and thus can reduce the rate of hydrogen evolution $[49,50]$. The schematic representation of electrostatic interaction of protonated DMHB molecules on the MS surface is shown in Fig. 9.

\subsection{Surface Morphology Studies}

\subsubsection{Scanning Electron Microscopy (SEM)}

The SEM images of surface of MS immersed in $0.5 \mathrm{M}$ $\mathrm{H}_{2} \mathrm{SO}_{4}$ and $0.5 \mathrm{M} \mathrm{HCl}$ solutions for $3 \mathrm{~h}$ in the absence and presence of the inhibitor DMHB are represented in Fig. 10a, b. The rough surface with pits and cracks indicate the uniform corrosion of the corroded sample. The SEM images of MS specimen immersed in (a) $0.5 \mathrm{M} \mathrm{H}_{2} \mathrm{SO}_{4}$ and (b) $0.5 \mathrm{M}$ $\mathrm{HCl}$ containing $3.0 \mathrm{mM}$ DMHB are shown in Fig. 11a, b, respectively. After the addition of the inhibitor, the metal surface has become smoother and this indicates a surface film of DMHB is formed.

\subsubsection{Atomic Force Microscopy (AFM)}

Figure 12a, $\mathrm{b}$ shows the AFM images of the polished specimen immersed in $0.5 \mathrm{M} \mathrm{H}_{2} \mathrm{SO}_{4}$ and $0.5 \mathrm{M} \mathrm{HCl}$ solution, respectively. The average surface roughness $\left(R_{\mathrm{a}}\right)$, root mean square (RMS) roughness $\left(R_{\mathrm{q}}\right)$ and peak-valley maximum $(P-V)$ values are calculated and recorded in Table 6. However, with $3 \mathrm{mM}$ DMHB in solution the surface of the MS test coupon gets smoothened in $\mathrm{H}_{2} \mathrm{SO}_{4}$ and $\mathrm{HCl}$ as shown in Fig. 13a, b. The decrease in the values of $R_{\mathrm{a}}$ and $R_{\mathrm{q}}$ observed

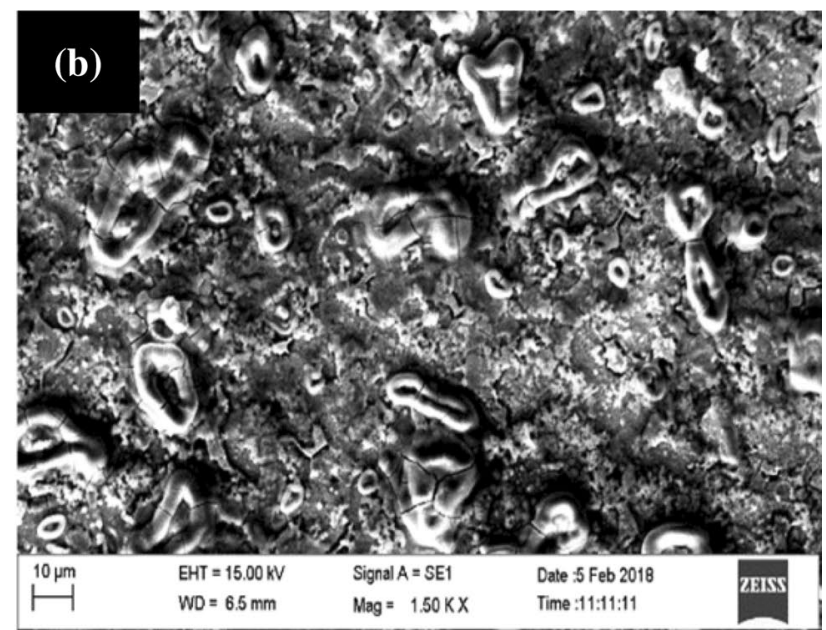

Fig. $10 \mathrm{SEM}$ images of mild steel specimen immersed in a $0.5 \mathrm{M} \mathrm{H}_{2} \mathrm{SO}_{4}$ and $\mathbf{b} 0.5 \mathrm{M} \mathrm{HCl}$ 

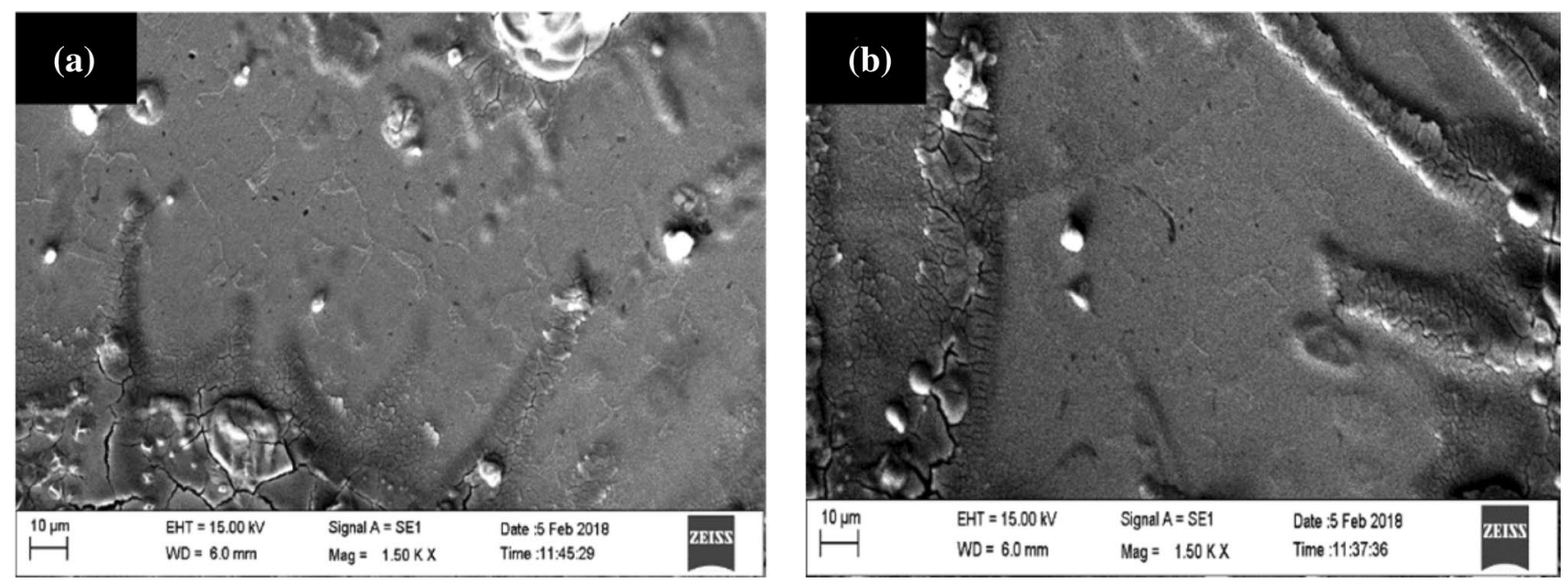

Fig. 11 SEM images of mild steel specimen immersed in a $0.5 \mathrm{M} \mathrm{H}_{2} \mathrm{SO}_{4}$ and $\mathbf{b} 0.5 \mathrm{M} \mathrm{HCl}$ containing $3.0 \mathrm{mM} \mathrm{DMHB}$
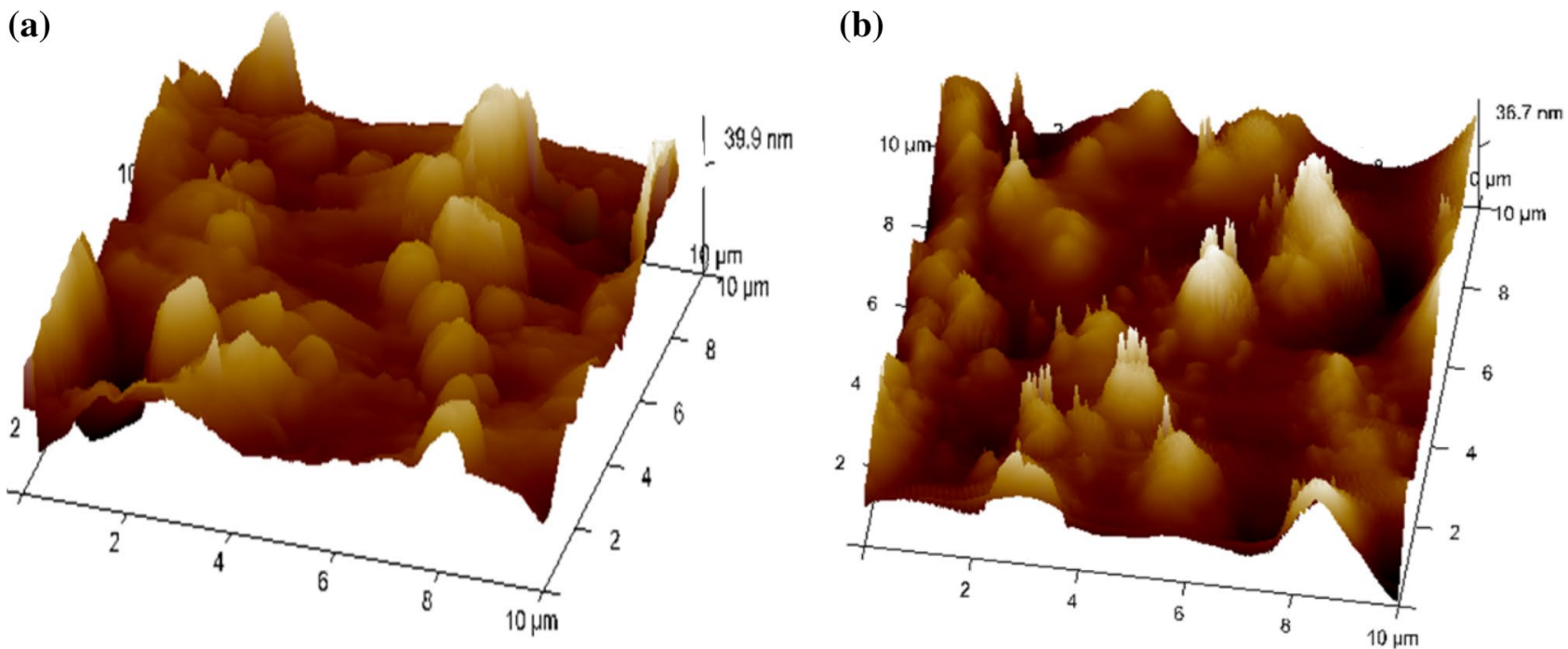

Fig. 12 AFM images of mild steel specimen immersed in a $0.5 \mathrm{M} \mathrm{H}_{2} \mathrm{SO}_{4}$ and b $0.5 \mathrm{M} \mathrm{HCl}$

Table 6 AFM results obtained for mild steel in $0.5 \mathrm{M} \mathrm{H}_{2} \mathrm{SO}_{4}$ and $0.5 \mathrm{M} \mathrm{HCl}$ in the absence and presence DMHB

\begin{tabular}{llll}
\hline Samples & $R_{\mathrm{a}}(\mathrm{nm})$ & $R_{\mathrm{q}}(\mathrm{nm})$ & $R_{\max }(\mathrm{nm})$ \\
\hline $\mathrm{MS}$ & 4.57 & 6.99 & 127 \\
$\mathrm{MS}+0.5 \mathrm{M} \mathrm{H}_{2} \mathrm{SO}_{4}$ & 113 & 157 & 1478 \\
$\mathrm{MS}+0.5 \mathrm{M} \mathrm{H}_{2} \mathrm{SO}_{4}+3 \mathrm{mM} \mathrm{DMHB}$ & 108 & 139 & 1161 \\
$\mathrm{MS}+0.5 \mathrm{M} \mathrm{HCl}$ & 206 & 291 & 3902 \\
$\mathrm{MS}+0.5 \mathrm{M} \mathrm{HCl}+3 \mathrm{mM}$ DMHB & 64.5 & 83.6 & 761 \\
\hline
\end{tabular}

in case of inhibited specimen was possibly due to the protective film of DMHB formed on the MS surface.

\subsection{Quantum Chemical Study}

The structure activity relationship between the molecular structure of DMHB and its inhibition efficiency was analysed by Quantum chemical calculations. The information about electron donating and proton accepting sites in the molecules, frontier molecular (HOMO and LUMO) orbital energies, the energy gap between HOMO and LUMO are calculated using DFT. The energy of the highest occupied molecular orbital $\mathrm{E}_{\mathrm{HUMO}}$ was found to be $-5.2926 \mathrm{eV}$ and that of lowest occupied molecular orbital $E_{\text {LUMO }}$ is $-1.2136 \mathrm{eV}$. The values of energy gap $\Delta E_{\text {gap }}$ and the fraction of electron transferred $\Delta N$ are calculated and recorded in Table 7. 

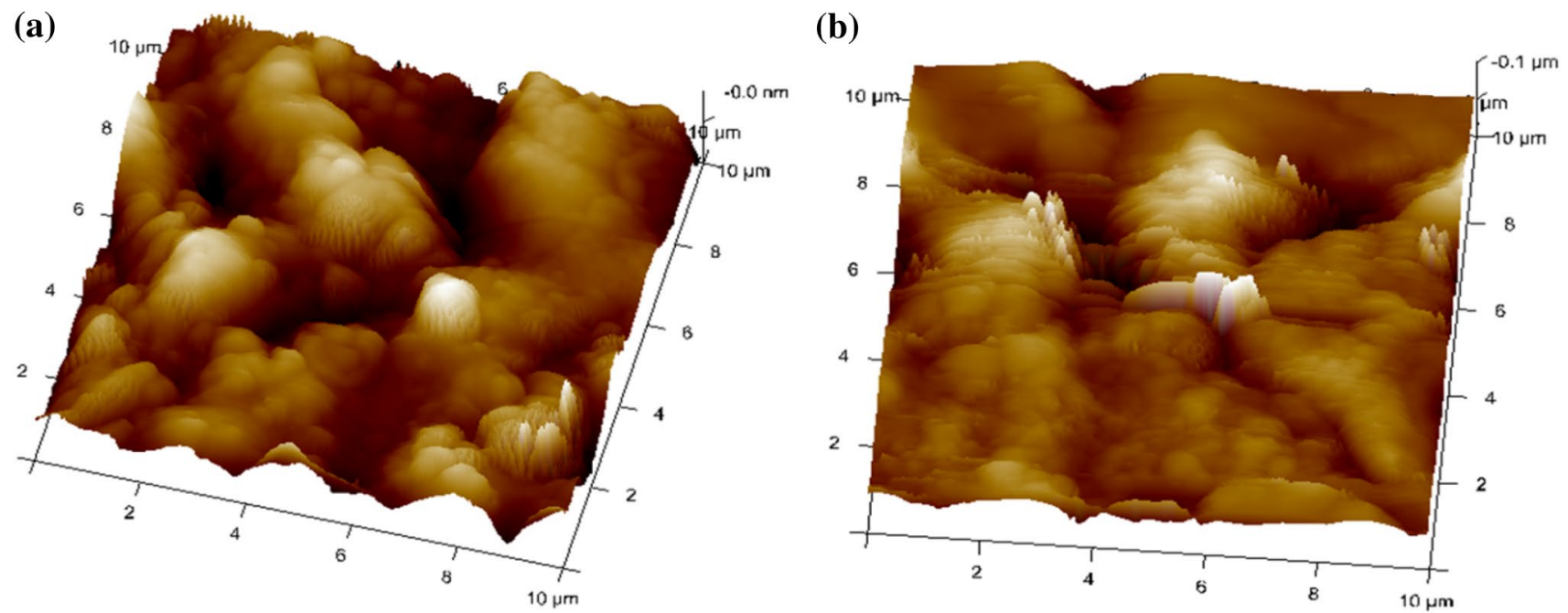

Fig. 13 AFM images of mild steel specimen immersed in a $0.5 \mathrm{M} \mathrm{H}_{2} \mathrm{SO}_{4}$ and $\mathbf{b} 0.5 \mathrm{M} \mathrm{HCl}$ containing $3.0 \mathrm{mM}$ DMHB

Table 7 Calculated quantum chemical parameters of DMHB

\begin{tabular}{lllll}
\hline Quantum parameters & $E_{\text {HОмо }}(\mathrm{eV})$ & $E_{\text {LUMO }}(\mathrm{eV})$ & $\Delta E(\mathrm{eV})$ & $\Delta N$ \\
\hline DMHB & -5.2926 & -1.2136 & 4.08 & 0.3841 \\
\hline
\end{tabular}

The optimized geometry, HOMO and LUMO of DMHB are shown in Fig. 14. The figure clearly shows the distribution of electron density is over the entire DMHB molecule. From Table 7, the high value of $E_{\mathrm{HUMO}}$ suggests that DMHB has tendency to provide electrons to suitable acceptor molecules possessing low energy or unfilled electron orbital. The lower the value of $\mathrm{E}_{\mathrm{LUMO}}$, the greater is the probability that the molecule will accept electrons [51, 52]. Whenever the value of $\Delta N$ is greater than zero, it suggests that the electron is transferred from the inhibitor molecule to the surface of the metal. In the literature, it is reported that if the value of $\Delta N$ is $<3.6$ then the inhibitor molecule has greater capability to donate the electrons [53]. From Table 7, it is observed that $\Delta N=0.3841$ and is lower than 3.6 which clearly shows that DMHB molecules have the ability of donating electrons to the vacant $d$ orbitals of the metal.

\subsection{Comparison of DMHB with the Reported Hydrazide Derivatives as Corrosion Inhibitors}

The inhibition efficiency of DMHB is further compared with other reported inhibitors [54-57] of similar type in Table 8

From the table, it can be inferred that DMHB is a potential inhibitor for corrosion inhibition of mild steel as it is showing nearly the similar inhibition efficiencies in comparison with the other reported inhibitors of this class. It is
Fig. 14 Optimized molecular structure and frontier orbitals distribution HOMO and LUMO of DMHB

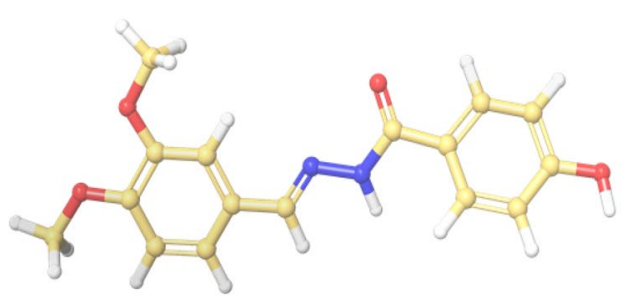

Optimized structure of DMHB

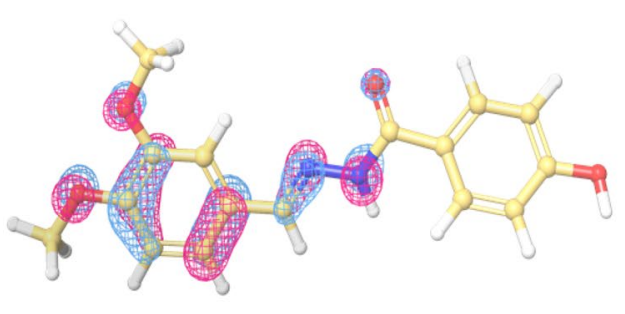

HOMO structure of DMHB

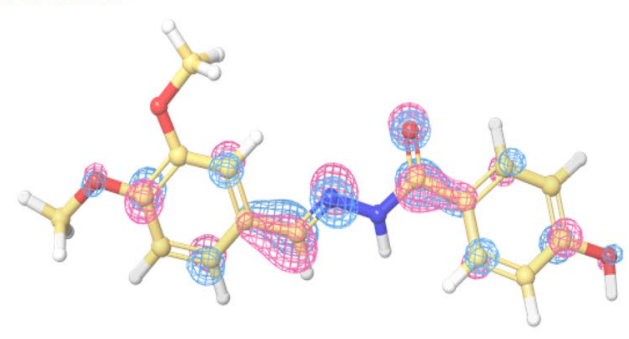

LUMO structure of DMHB 
Table 8 Comparison of DMHB with the reported hydrazide derivatives as corrosion inhibitors

\begin{tabular}{|c|c|c|c|c|c|c|}
\hline Acid media & Sample & Inhibitor & Structure & $\begin{array}{l}\text { Temp. } \\
(\mathrm{K})\end{array}$ & $\begin{array}{l}\text { \% IE at optimum } \\
\text { concentration }\end{array}$ & References \\
\hline $1 \mathrm{M} \mathrm{HCl}$ & Carbon steel & $\begin{array}{l}(E) \text { - } N \text { '-(2-hydroxyben- } \\
\text { zylidene) isonicotinohy- } \\
\text { drazide }\end{array}$ & & 303 & $94 \%$ at $5 \times 10^{-3} \mathrm{M}$ & {$[51]$} \\
\hline $1 \mathrm{M} \mathrm{HCl}$ & Stainless Steel & $\begin{array}{l}\text { 1-(1-(cyclohexa-2,4-di- } \\
\text { enyl)ethylidene)-2-(1- } \\
\text { phenylethylidene) } \\
\text { hydrazine }\end{array}$ & & 298 & $\begin{array}{l}86.3 \% \text { at } \\
21 \times 10^{6} \mathrm{M} \text { at }\end{array}$ & {$[52]$} \\
\hline $1 \mathrm{M} \mathrm{HCl}$ & Stainless Steel & $\begin{array}{l}\text { 1-benzylidene- } \\
\text { 2-(cyclohexa-2,4-dienyl- } \\
\text { methylene)hydrazine }\end{array}$ & & 298 & $\begin{array}{l}83.9 \% \text { at } \\
21 \times 10^{6} \mathrm{M}\end{array}$ & {$[52]$} \\
\hline $\begin{array}{l}1 \mathrm{M} \mathrm{HCl}, 0.5 \mathrm{M} \\
\mathrm{H}_{2} \mathrm{SO}_{4}\end{array}$ & Mild steel & $\begin{array}{l}\text { 2-(2-hydrazinyl-1,6-di- } \\
\text { hydro-6-oxopyrimidin- } \\
\text { 4-yl) acetohydrazide } \\
\text { (HDOP) }\end{array}$ & & 303 & $\begin{array}{c}85.4 \% \text { and } 72.3 \% \\
\text { at } 1 \times 10^{-2} \mathrm{M}\end{array}$ & [53] \\
\hline $1 \mathrm{~N} \mathrm{HCl}, 1 \mathrm{~N} \mathrm{H}_{2} \mathrm{SO}_{4}$ & Mild steel & $\begin{array}{l}\text { 4-(N,N-dimethylamino)- } \\
\text { benzaldehyde thiosemi- } \\
\text { carbazone }\end{array}$ & & 298 & $\begin{array}{l}95.7 \% \text { and } 97.8 \% \\
\text { at } 450 \mu \mathrm{M}\end{array}$ & [54] \\
\hline $\begin{array}{l}0.5 \mathrm{M} \mathrm{HCl}, 0.5 \mathrm{M} \\
\mathrm{H}_{2} \mathrm{SO}_{4}\end{array}$ & Mild steel & $\begin{array}{l}\text { N'-(3,4- } \\
\text { dimethoxybenzylidene)- } \\
\text { 4-hydroxybenzohy- } \\
\text { drazide }\end{array}$ & & 303 & $\begin{array}{c}81 \% \text { and } 86 \% \text { at } \\
3 \times 10^{-3} \mathrm{M}\end{array}$ & $\begin{array}{r}\text { Present } \\
\text { study }\end{array}$ \\
\hline
\end{tabular}

also seen that the maximum inhibition efficiency is obtained at a relatively lower concentration of $\left(3 \times 10^{-3} \mathrm{M}\right)$ of DMHB when compared to those reported in the table.

\subsection{Statistical Analysis}

\subsubsection{Optimization of Parameters for \% IE}

The response surface technique (RSM) relates to a combination of mathematical and statistical models that offer a method for problem analysis of a multivariable system. The RSM provides a platform to determine the optimized conditions in terms of input parameters to obtain a desired response [58]. This is a convenient technique to punctuate values with substantial variations and optimize the phenomena by minimizing the variability of outcomes. A Box Behnken Design (BBD) was executed to evaluate the effect of the temperature, $\mathrm{H}_{2} \mathrm{SO}_{4}$ concentration and DMHB concentration on the corrosion inhibition efficiency $(\%$ IE). All the variables were chosen at three levels as illustrated: temperatures of 3040 , and $50{ }^{\circ} \mathrm{C}$; concentration of DMHB-300, 600 and 900 ppm; concentration of acid-0.5, $0.75,1.0 \mathrm{M}$. The efficiency of the inhibitor and the factors
Table 9 Factors of BBD in coded and uncoded form

\begin{tabular}{lllc}
\hline Sl. no & Parameter & Code & Unit \\
\hline 1 & Temperature & A & ${ }^{\circ} \mathrm{C}$ \\
2 & $\mathrm{H}_{2} \mathrm{SO}_{4}$ concentration & B & $\mathrm{M}$ \\
3 & $\mathrm{DMHB}$ concentration & $\mathrm{C}$ & $\mathrm{ppm}$ \\
\hline
\end{tabular}

such as temperature and concentration of the medium was related through the obtained regression model.

The factors of RSM analysis in the coded and uncoded form are illustrated in Table 9.

Screening tests revealed that temperature, the concentration of DMHB inhibitor and concentration of acid remarkably influenced the \% IE. Accordingly, they were chosen as investigation factors for further examination. The impacts of temperature (A), the concentration of $\mathrm{H}_{2} \mathrm{SO}_{4}(\mathrm{~B})$ and concentration of DMHB (C) were found by strategies for a Box-Behnken design (BBD). To optimize the three individual factors, there were a total of 15 experimental runs in the BBD, which are listed in Table 10.

A quadratic model was developed to indicate the inhibitor efficiency as a function of the independent variables in the chosen ranges: 
Table 10 Actual and predicted results of \% IE acquired from the potentiodynamic polarization and Box-Behnken design

\begin{tabular}{llllll}
\hline Temp (A) & $\begin{array}{l}\text { Conc. } \\
\mathrm{H}_{2} \mathrm{SO}_{4} \\
(\mathrm{~B})\end{array}$ & $\begin{array}{l}\text { Conc. } \\
\text { DMHB } \\
(\mathrm{C})\end{array}$ & $\begin{array}{l}\text { Experi- } \\
\text { mental } \\
(\% \mathrm{IE})\end{array}$ & $\begin{array}{l}\text { Predicted } \\
(\% \mathrm{IE})\end{array}$ & RESIDUAL \\
\hline 30 & 0.50 & 600 & 76 & 78.25 & -2.25 \\
50 & 0.50 & 600 & 47 & 47.25 & -0.25 \\
30 & 1.00 & 600 & 56 & 55.75 & 0.25 \\
50 & 1.00 & 600 & 35 & 32.75 & 2.25 \\
30 & 0.75 & 300 & 32 & 27.75 & 4.25 \\
50 & 0.75 & 300 & 14 & 11.75 & 2.25 \\
30 & 0.75 & 900 & 70 & 72.25 & -2.25 \\
50 & 0.75 & 900 & 30 & 34.25 & -4.25 \\
40 & 0.50 & 300 & 31 & 33.00 & -2.00 \\
40 & 1.00 & 300 & 22 & 26.50 & -4.50 \\
40 & 0.50 & 900 & 83 & 78.50 & 4.50 \\
40 & 1.00 & 900 & 50 & 48.00 & 2.00 \\
40 & 0.75 & 600 & 60 & 58.00 & 2.00 \\
40 & 0.75 & 600 & 56 & 58.00 & -2.00 \\
40 & 0.75 & 600 & 58 & 58.00 & 0.00 \\
\hline
\end{tabular}

led to the increase of the inhibition efficiency. The quadratic term $A^{2}$ had a negative effect on the inhibition efficiency. This can be explained on the basis that higher temperature increases the corrosion rate and hence decreases the corrosion inhibition efficiency. The coefficient of determination $\left(R^{2}\right)$ obtained for the predictive model is 0.9803 , which reveals a good fit illustrating predicted model sufficiently reflecting the observed values. Hence, the output can be readily explained by the model [60].

The performance of the influence of three factors measured separately on \% IE is presented in Fig. 15. It illustrates the main effects of individual parameters. As the concentration of the DMHB increased from 300 to $900 \mathrm{ppm}$ (i.e. $1 \times 10^{-3} \mathrm{M}$ to $3 \times 10^{-3} \mathrm{M}$ ), the $\%$ IE increased, the reason being the coverage of the active sites on the metal with more and more DMHB molecules.

At $1 \mathrm{M} \mathrm{H}_{2} \mathrm{SO}_{4}$ concentration, the \% IE showed a drastic decrease due to the intensified corrosion attack on the metal. The inhibitor showed physisorption mode of adsorption as the \% IE decreased with an increase in temperature. The results are in line with the PDP and EIS study results.

The interactive effects of the process variables on the \%

$$
\begin{aligned}
\mathrm{IE}= & -98.0+4.95 \mathrm{~A}-87.0 \mathrm{~B}+0.3792 \mathrm{C}-0.0725 \mathrm{~A} * \mathrm{~A}+44.0 \mathrm{~B} * \mathrm{~B} \\
& -0.000158 \mathrm{C} * \mathrm{C}+0.800 \mathrm{~A} * \mathrm{~B}-0.001833 \mathrm{~A} * \mathrm{C}-0.0800 \mathrm{~B} * \mathrm{C}
\end{aligned} .
$$

The positive sign indicates the favourable effects of the independent parameter on the response, while the negative sign indicates the reverse effect [59].

Regression coefficient of Eq. (12) explained that A and $\mathrm{C}$ have positive effect, while $\mathrm{B}$ has negative effect on the inhibitor efficiency. Likewise, an interaction term $\mathrm{AC}$ was favourable for decreasing inhibition efficiency, while the $A B$
IE were investigated by plotting a two-dimensional contour against two independent variables. Figure 16 shows the two-dimensional contour plots for the response. The corrosion inhibition efficiency was at the highest value when the DMHB concentration was 900 ppm and $\mathrm{H}_{2} \mathrm{SO}_{4}$ concentration was $0.5 \mathrm{M}$ as indicated by Fig. 16a. While temperature and inhibitor concentration were considered for their effect
Fig. 15 Main effects plot for $\%$ $I E$ for $\mathrm{MS}$ in $\mathrm{H}_{2} \mathrm{SO}_{4}$

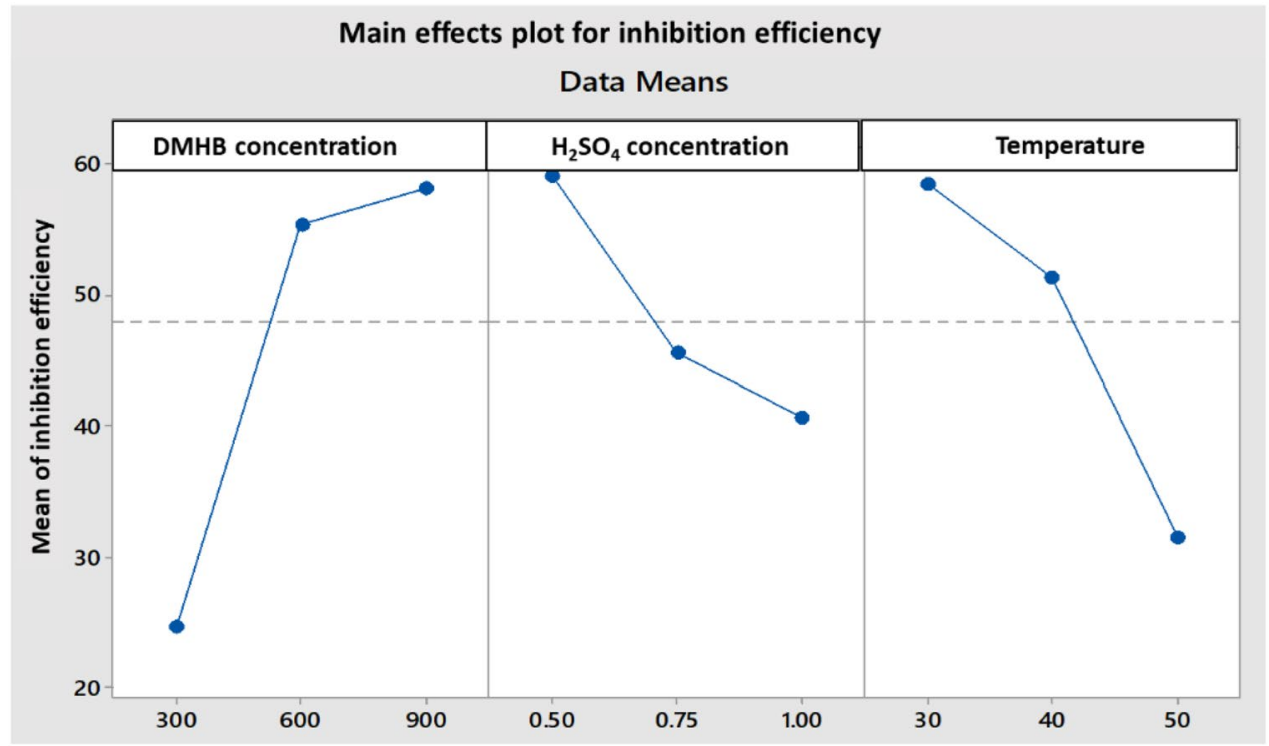



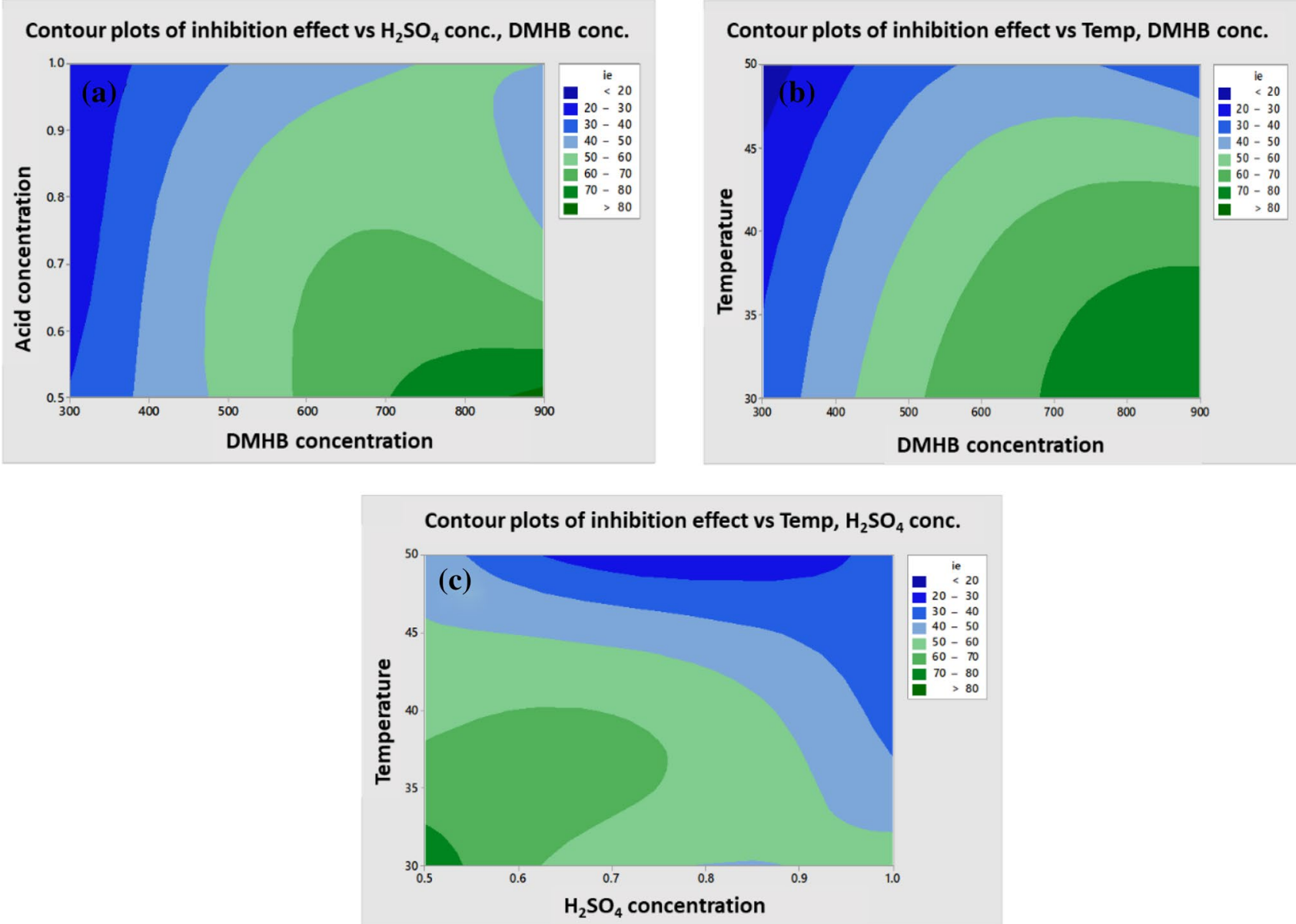

Fig. 16 Contour plots correlating dependent and independent variables

on the response, the best output response was found at room temperature and 900 ppm concentration of the inhibitor. Figure 16c depicts the appearance of highest \% IE at the lowest study temperature and $\mathrm{H}_{2} \mathrm{SO}_{4}$ concentration.

\subsubsection{Response Optimization}

Response optimization of the model in Eq. (12) was carried out to determine the concentration of DMHB and temperature at which the corrosion rate of MS was at a minimum in $\mathrm{H}_{2} \mathrm{SO}_{4}$ to facilitate the maximum \% IE. The desirability function method was applied to optimize the process factors for the maximum possible inhibition efficiency. Figure 17 shows the response optimization plot of the \% IE. The optimum parameter was $300 \mathrm{~K}$ at $\mathrm{H}_{2} \mathrm{SO}_{4}$ concentration of $0.5 \mathrm{M}$ and DMHB concentration of $900 \mathrm{ppm}$ which gave the best output response of $90 \%$ inhibition efficiency.

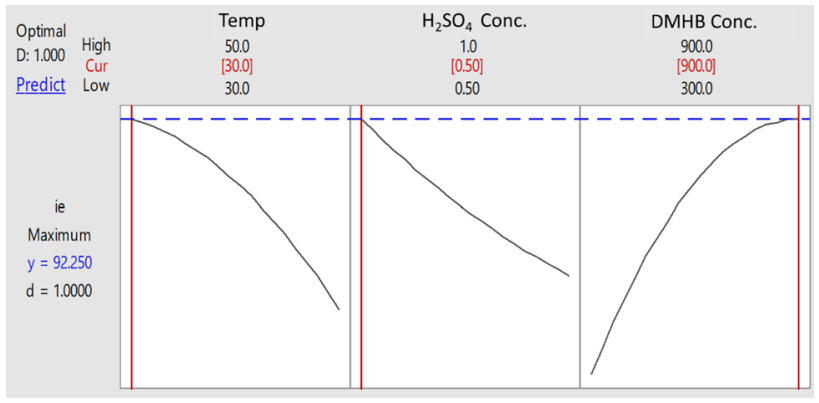

Fig. 17 Response optimization plots for corrosion inhibition efficiency

\section{Conclusions}

The conclusions drawn from the present study are as follows: 
1. DMHB acts as a mixed inhibitor.

2. Percentage inhibition efficiency increased with the increase in DMHB concentration and decreased with temperature increase.

3. The maximum inhibition efficiency shown by DMHB at its optimum concentration $\left(3 \times 10^{-3} \mathrm{M}\right)$ was about $90 \%$.

4. The corrosion rates obtained by Tafel extrapolation technique are in agreement with EIS results.

5. Adsorption of DMHB on MS surface in acid media follows Langmuir adsorption isotherm.

6. Inhibition efficiency exhibited by DMHB is substantiated by DFT calculations.

7. The coefficient of determination $\mathrm{R}^{2}$ obtained was 0.9803 comprehending that the actual results fit well with the predicted results applying the quadratic model.

Funding Open access funding provided by Manipal Academy of Higher Education, Manipal.

\section{Compliance with Ethical Standards}

Conflict of interest The corresponding author states that there is no conflict of interest.

Open Access This article is licensed under a Creative Commons Attribution 4.0 International License, which permits use, sharing, adaptation, distribution and reproduction in any medium or format, as long as you give appropriate credit to the original author(s) and the source, provide a link to the Creative Commons licence, and indicate if changes were made. The images or other third party material in this article are included in the article's Creative Commons licence, unless indicated otherwise in a credit line to the material. If material is not included in the article's Creative Commons licence and your intended use is not permitted by statutory regulation or exceeds the permitted use, you will need to obtain permission directly from the copyright holder. To view a copy of this licence, visit http://creativecommons.org/licenses/by/4.0/.

\section{References}

1. Gunavathy N, Murugavel SC (2013) Study on the effect of Musa Acuminata flower extract on the corrosion inhibition of mild steel in $1 \mathrm{~N} \mathrm{H}_{2} \mathrm{SO}_{4}$. Int $\mathrm{J}$ Chem Sci 11:475-486

2. Umoren SA, Eduok UM, Oguzie EE (2008) Corrosion inhibition of mild steel in $1 \mathrm{M} \mathrm{H}_{2} \mathrm{SO}_{4}$ by polyvinyl pyrrolidone and synergistic iodide additives. Portugaliae Electrochim Acta 26:533-546

3. Ramses GI, Benjamin VS, Michael SW (2014) Corrosion inhibitor patents in industrial applications - a review, recent patents on corrosion. Science. https://doi.org/10.2174/22106839036661312172 33723

4. Mauro JB, Jose AC, Claudio AG, Marı́a VM (2014) Corrosion inhibition of mild steel in sulphuric acid using a bicyclic thiadiazolidine. J Appl Electrochem. https://doi.org/10.1007/s1080 0-014-0729-4

5. Sathyanarayanan S, Marikkannu C, Palaniswamy N (2005) Corrosion inhibition effect of tetramines for mild steel in $1 \mathrm{M} \mathrm{HCl}$. Appl Surf Sci 241:477-484
6. Aouniti A, Elmsellem H, Tighadouini S, Elazzouzi M, Radi S, Chetouani A, Hammouti B, Zarrouk A (2016) Schiff's base derived from 2-acetyl thiophene as corrosion inhibitorof steel in acidic medium. J Taibah Univ Sci 10:774-785

7. Abd El-Maksoud SA (2008) The effect of organic compounds on the electrochemical behaviour of steel in acidic media. Int $\mathbf{J}$ Electrochem Sci 3:528-555

8. Ashassi-Sorkhabia H, Shaabanib B, Seifzadeh D (2005) Corrosion inhibition of mild steel by some Schiff base compounds in hydrochloric acid. Appl Surf Sci 239:154-164

9. El Defrawy AM, Abdallah M, Al-Fahemi JH (2019) Electrochemical and theoretical investigation for some pyrazolone derivatives as inhibitors for the corrosion of C-steel in $0.5 \mathrm{M}$ hydrochloric acid. J Mol Liq 288:110994. https://doi.org/10.1016/j.molli q.2019.110994

10. Abdallah M, Fawzy A, Hawsawi H (2020) Maltodextrin and chitosan polymers as inhibitors for the corrosion of carbon steel in 1.0 M hydrochloric acid. Int J Electrochem Sci 15:5650-5663. https://doi.org/10.20964/2020.06.82

11. Meng Y, Ning W, Xu B, Yang W, Zhang K, Chen Y, Li L, Liu $X$, Zhenga J, Zhang Y (2017) Inhibition of mild steel corrosion in hydrochloric acid using two novel pyridine Schiff base derivatives: a comparative study of experimental and theoretical results. RSC Adv 7:43012-43014

12. Kamal C, Sethuraman MG (2012) Caulerpin-A bis-indole alkaloid as a green inhibitor for the corrosion of mild steel in $1 \mathrm{M} \mathrm{HCl}$ solution from the marine alga caulerpa racemosa. Ind Eng Chem Res 51:10399-10407. https://doi.org/10.1021/ie3010379

13. Saliyan R, Adhikari V (2008) Quinolin-5-ylmethylene-3-\{[8(trifluoromethyl) quinolin-4-yl] thio \}propanohydrazide as an effective inhibitor of mild steel corrosion in $\mathrm{HCl}$ solution. Corros Sci 50:55-61

14. Mohan P, Arunsunai Kumar K, Paruthimal Kaliagnan G, Muralidharan VS (2012) N'-(4-Methoxybenzylidene) benzohydrazide as effective corrosion inhibitor for mild steel in $1 \mathrm{M} \mathrm{HCl}$. Asian J Chem 24:5821-5823

15. Fouda AS, Mohamed MT, Soltan MR (2013) Role of some benzohydrazide derivatives as corrosion inhibitors for carbon steel in $\mathrm{HCl}$ Solution. J Electrochem Sci Technol 4:61-70

16. Yadav M, Sinha RR, Kumar S, Bahadur I, Ebenso EE (2015) Synthesis and application of new acetohydrazide derivatives as a corrosion inhibition of mild steel in acidic medium: insight from electrochemical and theoretical studies. J Mol Liq 208:322-332

17. Larabi L, Harek Y, Benali O, Ghalemb S (2005) Hydrazide derivatives as corrosion inhibitors for mild steel in $1 \mathrm{M} \mathrm{HCl}$. Prog Org Coat 54:256-262

18. Khaled KF, Elhabib OA, El-mghraby A, Ibrahim OB, Magdy Ibrahim AM (2010) Inhibitive effect of thiosemicarbazone derivative on corrosion of mild steel in hydrochloric acid solution. J Mater Environ Sci 3:139-150

19. El-Shafei AA, Moussa MNH, El-Far AA (2001) The corrosion inhibition character of thiosemicarbazide and its derivatives for C-steel in hydrochloric acid solution. Mat Chem Phy 70:175-180

20. Saliyan R, Adhikari V (2009) Corrosion inhibition of mild steel in acid media by quinolinylthiopropanohydrazones. Indian J Chem Technol 16:162-174

21. Goulart CM, Souza AE, Huitle CAM, Rodrigues CJF, Maciel MAM, Echevarria A (2013) Experimental and theoretical evaluation of semicarbazones and thiosemicarbazones as organic corrosion inhibitors. Corr Sci 67:281-291

22. Abd Ei-Rehim SS, Ibrahim MAM, Khaled KK (1999) 4- Aminoantipyrine as an inhibitor of mild steel corrosion in $\mathrm{HCl}$ solution. J Appl Electrochem 29:593-599

23. Khaled KF (2006) Experimental and theoretical study for corrosion inhibition of mild steel in hydrochloric acid solution by 
some new hydrazine carbodithioic acid derivatives. Appl Surf Sci 252:4120-4128

24. Shetty D, Kumari PP, Rao SA, Shetty P (2020) Anticorrosion behaviour of a hydrazide derivative on $6061 \mathrm{Al}-15 \%(\mathrm{v}) \mathrm{SiC}_{(\mathrm{P})} \mathrm{com}-$ posite in acid medium: experimental and theoretical calculations. J Bio- and Tribo-Corros 6:59-74

25. Yudhistira R, Kumari P, Sunil D, Shetty P, Rao SA (2019) Attenuation of acid corrosion of mild steel using a novel organic dye: electrochemical and Surface Measurements. Surf Eng Appl Electrochem 55:443-454

26. Lee C, Yang W, Parr RG (1988) Development of the Colle-Salvetti correlation-energy formula into a functional of the electron density. Phys Rev condense mater B 37:785-789

27. Singh P, Ebenso EE, Olasunkanmi LO, Obot IB, Quraishi MA (2016) Electrochemical theoretical and surface morphological studies of corrosion inhibition effect of green naphthyridine derivative on mild steel in hydrochloric acid. J Phys Chem C 120:3408-3419

28. Kumari PP, Shetty P, Rao SA (2014) Electrochemical measurements for the corrosion inhibition of mild steel in $1 \mathrm{M}$ hydrochloric acid by using an aromatic hydrazide derivative. Arab J Chem 9:1878-5352

29. Kumari P, Shetty P, Rao SA, Sunil D (2017) Inhibition behaviour of 2-[(2-methylquinolin-8-yl) oxy]acetohydrazide on the corrosion of mild steel in hydrochloric acid solution. Trans Indian Inst Met 70:1139-1150

30. Li W, He Q, Pei C, Houa B (2007) Experimental and theoretical investigation of the adsorption behaviour of new triazole derivatives as inhibitors for mild steel corrosion in acid media. Electrochem Acta 52:6386-6394

31. Li W, He Q, Zhang S, Pei C, Hou B (2008) Some new triazole derivatives as inhibitors for mild steel corrosion in acidic medium. J Appl Electrochem 38:289-295

32. Lowmunkhong P, Ungthararak D, Sutthivaiyakit P (2010) Tryptamine as a corrosion inhibitor of mild steel in hydrochloric acid solution. Corr Sci 52:30-36

33. Bentiss F, Lebrini M, Lagrenee M (2005) Thermodynamic characterization of metal dissolution and inhibitor adsorption processes in mild steel/ 2,5-bis(nthienyl)-1,3,4-thiadiazoles/ hydrochloric acid system. Corr Sci 47:2915-2931

34. Hagazy MA, Zaky MF (2010) Inhibition effect t of novel nonionic surfactants on the corrosion of carbon steel in acidic medium. Corr Sci 52:1333-1341

35. Prasanna BM, Praveen BM, Hebbar N, Venkatesha TV, Tandon HC (2016) Inhibition study of mild steel corrosion in $1 \mathrm{M}$ hydrochloric acid solution by 2 -chloro 3 -formyl quinolone. Int $\mathrm{J}$ Ind Chem 7:9-19

36. McCafferty E (2010) Introduction to corrosion science. Springer, Berlin

37. Loto RT, Loto CA, Olaitan A, Babalola P (2017) Evaluation of the synergistic properties of 4-hydroxy-3-methoxybenzaldehyde and 1, 4-diaminobenzene on the electrochemical corrosion behaviour of mild steel in dilute acid solutions. Mol J Chem 5:81-95

38. Singh AK, Quraishi MA (2011) Adsorption properties and inhibition of mild steel corrosion in hydrochloric acid solution by ceftobiprole. J Appl Electrochem 41:7-18

39. Singh AK, Quraishi MA (2010) Inhibiting effects of 5-substituted isatin-based Mannich beases on the corrosion of mild steel in hydrochloric acid solution. J Appl Electrochem 40:1293-1306

40. Ahamad I, Prasad R, Quraishi MA (2010) Thermodynamic, electrochemical and quantum chemical investigation of some Schiff bases as corrosion inhibitors for mild steel in hydrochloric acid solutions. Corr Sci 52:933-942

41. Soltani N, Behpour M, Ghoreishi SM, Naeimi H (2010) Corrosion inhibition of mild steel in hydrochloric acid solution by some double Schiff bases. Corr Sci 52:1351-1361
42. Shivakumar SS, Mohana KN (2013) Studies on the inhibitive performance of cinnamomum zeylanicum extracts on the corrosion of mild steel in hydrochloric acid and sulphuric acid media. J Mater Environ Sci 5:4448-4459

43. Zhang L, He Y, Zhou Y, Yang R, Yang Q, Qing D, Niu Q (2015) A novel imidazoline derivative as corrosion inhibitor for P110 carbon steel in hydrochloric acid environment. Petroleum 1:237-243

44. Behpour M, Ghoreishi SM, Soltani N, Salavati-Niasari M, Hamadanian M, Gandomi A (2008) Electrochemical and theoretical investigation on the corrosion inhibition of mild steel by thiosalicylaldehyde derivatives in hydrochloric acid solution. Corr Sci 50:2172-2181

45. Neelima M, Singh MM (2011) Investigation of passive film properties and pitting resistance of AISI 316 in aqueous ethanoic acid containing chloride ions using electrochemical impedance spectroscopy (EIS). Port Electrochim Acta 29:233-251

46. Shaju KS, Thomas KJ, Raphael VP, Paul A (2013) Electrochemical and surface morphological studies of carbon steel corrosion by a novel polynuclear schiff base in $\mathrm{HCl}$ solution. ISRN Electrochem 55:1-8

47. Popova A, Sokolova E, Raicheva S, Christov M (2003) AC and DC study of the temperature effect on mild steel corrosion in acid media in the presence of benzimidazole derivatives. Corr Sci 45:33-58

48. Mallaiya K, Subramaniam R, Srikandan SS, Gowri S, Rajasekaran N, Selvaraj A (2011) Electrochemical characterization of the protective film formed by the unsymmetrical Schiff's base on the mild steel surface in acid media. Electrochim Acta 56:3857-3863

49. Popova A, Christov M, Raicheva S, Sokolova E (2004) Adsorption and inhibitive properties of benzimidazole derivatives in acid mild steel corrosion. Corr Sci 46:1333-1350

50. de Oliveira RB, de Souza-Fagundes EM, Soares RPP, Andrade AA, Krettli AU, Zani CL (2008) Synthesis and antimalarial activity of semicarbazone and thiosemicarbazone derivatives. Eur J Med Chem 43:1983-1988

51. Awad MK, Mustafa MR, Elnga MMA (2010) Computational simulation of the molecular structure of some triazoles as inhibitors for the corrosion of metal surface. J Mol Struct 959:66-74

52. Gece G (2008) The use of quantum chemical methods in corrosion inhibitor studies. Corros Sci 50:2981-2992

53. Babic-Samardzija K, Khaled KF, Hackerman N (2005) The einvestigation of the inhibiting action of $\mathrm{O}-, \mathrm{S}-$ and $\mathrm{N}$ - dithiocarbamato (1,4,8,11-tetraazacyclotetra decane)cobalt(III) complexes on the corrosion of iron in $\mathrm{HClO}_{4}$ acid. Appl Surf Sci 240:327-340

54. Chaouiki A, Lgaz H, Salghi R, Gaonkar SL, Bhat KS, Jodeh S, Toumiat K, Oudda H (2019) New benzohydrazide derivative as corrosion inhibitor for carbon steel in a $1.0 \mathrm{M} \mathrm{HCl}$ solution: electrochemical, DFT and Monte Carlo simulation studies. Port Electrochim Acta 37:147-165

55. Fouda AS, Abd El-Maksoud SA, El-Hossiany A, Ibrahim A (2019) Evolution of the corrosion-inhibiting efficiency of novel hydrazine derivatives against corrosion of stainless steel 201 in acidic medium. Int J Electrochem Sci 14:6045-6064

56. Zeinab A, Abdallah Mohamed S, Ahmed M, Saleh MM (2016) Organic synthesis and inhibition action of novel hydrazide derivative for mild steel corrosion in acid solutions. Mater Chem Phys 174:91-99

57. Mourya P, Banerjee S, Rastogi RB, Singh MM (2013) The inhibition of mild steel corrosion in hydrochloric and sulphuric acid media using thiosemicarbazone derivative. Ind Eng Chem Res 52:12733-12747

58. Ribeiro Filho SLM, Lauro CH, Bueno AHS, Brandão LC (2016) Influence cutting parameters on the surface quality and corrosion behavior of Ti-6Al-4V alloy in synthetic body environment (SBF) using Response Surface Method. Measurement 88:223-237 
59. Prakash T, Du HC, Min SK, Seong HJ (2019) Effects of granulation process variables on the physical properties of dosage forms by combination of experimental design and principal component analysis. Asian J Pharm 3:287-304

60. Luo X, Bai R, Zhen D, Yang Z, Huang D, Mao H, Li X, Zou H, Xiang Y (2019) Response surface optimization of the enzyme-based ultrasound-assisted extraction of acorn tannins and their corrosion inhibition properties. Ind Crops Prod 129:405-413

Publisher's Note Springer Nature remains neutral with regard to jurisdictional claims in published maps and institutional affiliations. 